\title{
Co-delivery of repurposing Itraconazole and VEGF siRNA by composite nanoparticulate system for collaborative anti-angiogenesis and anti-tumor efficacy against breast cancer
}

\section{Mingji Jin ( $\nabla_{\text {jinmingji@imm.ac.cn ) }}$}

Chinese Academy of Medical Sciences \& Peking Union Medical College Institute of Materia Medica

\section{Bowen Zeng}

Chinese Academy of Medical Sciences \& Peking Union Medical College Institute of Materia Medica Yanhong Liu

Chinese Academy of Medical Sciences \& Peking Union Medical College Institute of Materia Medica Li Jin

Yanbian University

\section{Yan Hou}

Chinese Academy of Medical Sciences \& Peking Union Medical College Institute of Materia Medica Chao Liu

Chinese Academy of Medical Sciences \& Peking Union Medical College Institute of Materia Medica

Wei Liu

Chinese Academy of Medical Sciences \& Peking Union Medical College Institute of Materia Medica

\section{Hao Wu}

Chinese Academy of Medical Sciences \& Peking Union Medical College Institute of Materia Medica

\section{Liqing Chen}

Chinese Academy of Medical Sciences \& Peking Union Medical College Institute of Materia Medica

\section{Zhonggao Gao}

Chinese Academy of Medical Sciences \& Peking Union Medical College Institute of Materia Medica

Wei Huang

Chinese Academy of Medical Sciences \& Peking Union Medical College Institute of Materia Medica

\section{Research Article}

Keywords: itraconazole, VEGF siRNA; breast cancer; co-inhibit

Posted Date: January 28th, 2022

DOI: https://doi.org/10.21203/rs.3.rs-1267572/v1 
License: (c) (i) This work is licensed under a Creative Commons Attribution 4.0 International License. Read Full License 


\section{Abstract}

Background: Combination of two different therapeutic modalities of VEGF inhibitors against angiogenesis can cooperatively impede breast cancer tumor growth and enhance therapeutic efficacy. Itraconazole (ITZ) is a conventional antifungal drug with high safety, but it has been repurposed to be a multitarget anti-angiogenesis agent for cancer therapy in recent years.

Results: In the present study, composite nanoparticles co-loaded with ITZ and VEGF siRNA were prepared in order to investigate their anti-angiogenesis efficacy and synergistic anticancer effect against breast cancer. The nanoparticles have suitable particle size $(117.9 \pm 10.3 \mathrm{~nm})$ and weak positive surface charge $(6.69 \pm 2.46 \mathrm{mV})$, as well as good stability and drug release profile in vitro. Moreover, the nanoparticles were successfully taken up by 4T1 cells and escaped from endosomes, and realized cell apoptosis and cell proliferation inhibition in vitro. In vitro and in vivo experiments showed that the nanoparticles successfully induced the silencing of VEGF-related expressions and inhibited angiogenesis. Furthermore, the in vivo results demonstrated that the co-loaded ITZ-siRNA ${ }^{V E G F}$ NPs could inhibit tumor growth effectively due to the combined anti-angiogenesis and anti-tumor effect, as well as low toxicity and little side effects.

Conclusions: Taken together, our study suggests that the as-prepared delivery vehicles are simple and safe nanoplatform that improve antitumor efficacy of VEGF siRNA and ITZ, which allows the repositioning of the generic drug ITZ as a great candidate for antitumor therapy.

\section{Background}

Combination therapy with anticancer drug and siRNA has been suggested to be an effective and synergistic strategy for the cancer treatment with advantages of enhancing therapeutic effects ${ }^{1,2}$. However, combined delivery of anticancer drug and siRNA remains challenging due to their different physical and chemical properties ${ }^{3}$. In our previous study, we designed and prepared a novel smart polymeric nanoparticle delivery system using polyethyleneimine-block-polylactic acid (PEI-PLA)/poly (ethylene glycol)-block-poly (L-aspartic acid sodium salt) (PEG-PAsp) to co-deliver small molecule drugs and siRNA ${ }^{4,5}$. The prepared complex nanoparticles co-loaded with chemotherapeutic drugs and siRNA exhibited a good synergistic effect and had a good inhibitory effect on both non-small cell lung cancer and breast cancer. In addition, this kind of carrier system has the advantages of easy preparation, high stability and low toxicity, and it is necessary and important to expand its application range.

Drug repurposing represents the identification of the novel pharmacological effects of conventional drugs, which is also cost-effective and time saving ${ }^{6}$. As the pharmacokinetics, pharmacodynamics and safety of traditional drugs have been established, expanding the application of this drug in other diseases is also a rapid and risk-free way to develop new drug. Itraconazole (ITZ) is a broad-spectrum antifungal drug with triazole ring, of which the mechanism is to inhibit the synthesis of ergosterol mediated by cytochrome P450 oxidase and change the permeability of fungal cell membrane ${ }^{7}$. In recent years, 
researchers have found that ITZ has antitumor effect, which has changed people's understanding of its traditional identity as an antifungal agent ${ }^{8}$. Preclinical and clinical evidence confirmed the activity of ITZ against different cancers, rationalizing its potential repurposing as chemotherapeutic agent ${ }^{6}$. Wang ${ }^{9}$ et al. administered ITZ to MCF-7 and SKBR-3 nude mice bearing human breast cancer and observed its antitumor effect in vitro and in vivo. The results showed that ITZ could induce tumor volume reduction and promoted apoptosis and autophagy in tumor bearing mice. Some studies ${ }^{10}$ have found that ITZ can block the growth of tumor vascular endothelial cells in $\mathrm{G} 1$ phase, and then inhibit tumor angiogenesis. Interestingly, ITZ has a high affinity for fungal cytochrome P450 and a low affinity for human cytochrome P450 7,11 , thus being considered to be a potential antitumor drug with low toxicity.

Vascular endothelial growth factor (VEGF) is a member of angiogenic factor family, which is also a key point in promoting angiogenesis ${ }^{12}$. As a factor with high expression in most solid tumors, VEGF silencing can cause the apoptosis of vascular endothelial cells, and blocking VEGF can directly inhibit the growth of tumors ${ }^{13,14}$. Since VEGF is identified as the ideal RNAi candidate for breast cancer treatment, RNAimediated silencing of VEGF has demonstrated great capability of VEGF expression inhibition ${ }^{15}$. Angiogenesis is a kind of excessive proliferation of irregular blood vessels in the tumor microenvironment, which occurs in a wide spectrum of cancer ${ }^{16,17}$. Growing tumors require new blood vessels to supply nutrients and oxygen, so angiogenesis inhibitors have been proposed as anticancer drugs $^{18}$. As the progression of breast cancer is more intensely dependent on angiogenesis than others, a dual-targeting approach against angiogenesis and breast cancer cell proliferation would synergistically enhance therapeutic efficacy ${ }^{19}$.

The combination of ITZ and other drugs may be a potential therapy for breast cancer. By studying the anticancer mechanism of ITZ, Nacev and others ${ }^{20}$ confirmed that ITZ can significantly inhibit the binding of VEGF and VEGF receptor 2 (VEGFR2). The combination of ITZ and VEGF monoclonal antibody also exerted better synergistic effect. Hara and others ${ }^{21}$ found that ITZ and bevacizumab, a monoclonal antibody with anti VEGF function, played a synergistic role in anti-angiogenesis. These theories further enrich the mechanism of ITZ in antitumor vascular proliferation and provide the basis for tumor treatment. Therefore, ITZ co-loaded with VEGF siRNA would be a good strategy for anti-angiogenesis chemotherapy. However, ITZ has a highly hydrophobic weak base group with low solubility in water (about $1 \mathrm{ng} / \mathrm{ml}$ ) 22, 23, while VEGF siRNA is hydrophilicity high molecular weight drug. The most challenging problem is efficient delivery of both ITZ and VEGF siRNA into specific target tissues without toxic side effects.

Our team's previous research has already confirmed that the PEI-PLA and PEG-PAsp delivery system is very effective for co-loading anticancer drugs and siRNAs. In further research on synergistic effect of antiangiogenesis chemotherapy, we continue to choose PEI-PLA and PEG-PAsp as a drug delivery system to co-load the extremely hydrophobic ITZ and hydrophilic VEGF siRNA. The prepared complex nanoparticles are expected to be stable in the blood stream ( $\mathrm{pH} \mathrm{7.4)}$ and tumor extracellular environment (pH 6.5). Once entering tumor cells via EPR effect, the PEG-PAsp block will become neutral in acid endosomal 
environment ( $\mathrm{pH} 5.0$ - 6.0) and therefore detach from the complex nanoparticles. Finally, lysosomal escape occurred due to the "proton sponge effect" of PEl, and the drugs were successfully released to tumor cells. Under the combined effect of the two types of drugs, the co-loaded nanoparticles can synergistically inhibit tumor angiogenesis and thus play an antitumor role against breast cancer.

\section{Results And Discussion}

\section{Synthesis and characterization of PEI-PLA copolymer}

The synthesis of PEI-PLA was prepared by amino reaction between the carboxyl group of PLA-COOH and amino groups of PEI (Figure 2A). In the ${ }^{1} \mathrm{H}-\mathrm{NMR}$ spectrum (Figure 2B), the peak of PEl appears at around $2.6 \mathrm{ppm}^{24}$. In PEI-PLA, a new broad peak appears in 2.3-3.4 ppm, which is attributed to the protons of methylene $\left(-\mathrm{CH}_{2} \mathrm{CH}_{2}-\right)$ in PEl. The signals at $\delta=1.20 \mathrm{ppm}$ and $\delta=4.08 \mathrm{ppm}$ corresponded to the $-\mathrm{CH}_{3}$ and $(-\mathrm{CH})$ proton in the PLA block of PEI-PLA, respectively. As shown in the figure $2 \mathrm{C}$, strong absorption appears at $1755 \mathrm{~cm}^{-1}$ in the FTIR of PLA-COOH, which is attributed to the stretching vibration absorption peak $\left(\mathrm{V}_{\mathrm{C}=0}\right)$ of the carboxyl group in PLA-COOH. In PEI-PLA, strong absorption appeared at $3300 \mathrm{~cm}^{-1}$ and $1540-1640 \mathrm{~cm}^{-1}$, of which $3300 \mathrm{~cm}^{-1}$ was attributed to the absorption peak of amino on $\mathrm{PEI}$, and $1540-1640 \mathrm{~cm}^{-1}$ was attributed to the characteristic absorption peak of $\mathrm{C}=0$ stretching vibration in the amide bond. The results showed that the target molecule is successfully synthesized according to the reaction.

\section{Characterization of the nanoparticles}

The nanocarriers with a core-shell copolymeric structure and PEGylation on the surface were formulated by a three-step method of dialysis for the core and complex coacervation method for siRNA loading and PEGylation (Figure 3A). PLA, which is a good hydrophobic and biodegradable copolymer, was chosen to encapsulate the extremely hydrophobic ITZ in the core of the ITZ-siRNAVEGF NPs. In the previous study 4 , the optimal carrier material ratio of N/P 30 and $\mathrm{C} / \mathrm{N}$ ratio $1 / 5$ was selected by orthogonal experiments. Thus, at this optimal ratio we successfully formulated a nanocarrier. Particle size and zeta potential of ITZ-siRNAVEGF NPs measured by dynamic light scattering (DLS) were $117.9 \pm 10.3 \mathrm{~nm}$ and $6.69 \pm 2.46$ $\mathrm{mV}$ (Figure 3B). The satisfactory PDI of ITZ-siRNA ${ }^{\mathrm{VEGF}}$ NPs (PDI of $0.134 \pm 0.072$ ) indicates a narrow, uniform, homogenous distribution, and successful development of the formulation. The morphology images of ITZ-siRNAVEGF NPs from TEM (Figure 3B) further demonstrated that the NPs were spherical with smooth surface. Many researchers believe that weakly positive nanoparticles in the appropriate particle size range can be less readily absorbed, and make the best use of EPR effect ${ }^{25,26}$. So the slightly positive zeta potential after PEGylation of the ITZ-siRNAVEGF NPs reduces the chances of interaction of nanoparticles with phagocytes and their absorption by these cells. This shielding effect of PEG enhances the stability of the NPs especially, and also helps to improve circulation time in vivo by shielding recognition by the reticular endothelial system (RES) in the body ${ }^{17,27}$. ITZ is an extremely poorly watersoluble $\left(\sim 1 \mathrm{ng} / \mathrm{mL}\right.$ in water) molecule with high lipophilicity $(\log P 5.66)^{28,29}$. Herein, we encapsulated 
ITZ into nano-sized suspension to increase the solubility to enable intravenous administration. The EE of ITZ was $90.26 \pm 2.60 \%$ and the DL was $8.28 \pm 0.52 \%$. The results of gel imaging also showed that when $\mathrm{N} / \mathrm{P}$ ratio was 30 and $\mathrm{C} / \mathrm{N}$ ratio was 1/5, VEGF siRNA could completely shrink. Even after ITZ was encapsulated in the hydrophobic core, siRNA shrinkage was not affected (Figure 3C). In addition, we further accessed the stability of ITZ-siRNAVEGF NPs in PBS buffer and PBS buffer containing $10 \%$ FBS, which is an indication of their aggregation behavior in vivo after systemic administration. This was evaluated by measuring their particle size changes over time. As showed in Figure 3D, under the conditions of two buffers, the particle size of ITZ-siRNA ${ }^{\mathrm{VEGF}}$ NPs remained slightly changed within $6 \mathrm{~h}$, and the change range of particle size within $24 \mathrm{~h}$ was no more than $10 \mathrm{~nm}$.

To confirm the $\mathrm{pH}$-responsive sheddable ability of PEG-PAsp, we evaluated the particle size, zeta potential and PDI of ITZ-siRNAVEGF NPs under different $\mathrm{pH}$ values. The results indicate that the size decreased from $123.1 \pm 11.4 \mathrm{~nm}$ to $88.3 \pm 9.2 \mathrm{~nm}$, the zeta potential increased from $6.6 \pm 1.2 \mathrm{mV}$ to $21.7 \pm 5.6 \mathrm{mV}$ as the $\mathrm{pH}$ value decreased from 8.0 to 5.0 (Table 1), which indicating the PEG-PAsp copolymer was detached from the NPs when the $\mathrm{pH}$ value was below 6.0. These results verified our hypothesis that the PEG-PAsp block will become neutral in endosome ( $\mathrm{pH} 5.0$ - 6.0) and therefore detach from the complex nanoparticles.

Table 1. Particle sizes and zeta potentials of ITZ-siRNA ${ }^{\text {VEGF }}$ NPs at different $\mathrm{pH}$ values revealed $\mathrm{pH}$ dependent attatchment and disattatchment of PEG-PAsp under acidic conditions.

\begin{tabular}{llll} 
ITZ-siRNAVEGF NPs & Size $(\mathrm{nm})$ & Zeta potantial $(\mathrm{mV})$ & PDI \\
\hline $\mathrm{pH} 5.0$ & $88.3 \pm 9.2$ & $21.7 \pm 5.6$ & $0.203 \pm 0.014$ \\
\hline $\mathrm{pH} 6.0$ & $90.2 \pm 7.5$ & $15.3 \pm 3.0$ & $0.211 \pm 0.008$ \\
\hline $\mathrm{pH} 7.0$ & $115.4 \pm 12.3$ & $7.4 \pm 2.1$ & $0.156 \pm 0.012$ \\
\hline $\mathrm{pH} 8.0$ & $123.1 \pm 11.4$ & $6.6 \pm 1.2$ & $0.152 \pm 0.014$
\end{tabular}

\section{In vitro release of ITZ}

A comparative drug release study of ITZ-siRNA VEGF NPs was performed in PBS at pH 5.5 and pH 7.4, simulating the acidic endosome and the normal physiological environment, respectively (Figure 3E). At $\mathrm{pH} 5.5$, after $72 \mathrm{~h}$, the release of ITZ from ITZ-siRNAVEGF NPs was about $80.74 \pm 4.58$, but at $\mathrm{pH} 7.4$, the accumulative release of ITZ from ITZ-siRNAVEGF NPs was $60.43 \pm 2.19$. The NPs released ITZ more quickly in the acid environment probably due to the detachment of PEG-PAsp outer and faster degradation of PLA core. Such behavior presumably enhances intracellular drug release once the complex NPs enter the tumor cells via endocytosis and trapped within the acidic endosomal compartments ${ }^{30}$. The drug release from polymeric nanocarrier systems involves several mechanisms such as polymer degradation, erosion of the polymer, desorption from the particle surfaces ${ }^{31}$. The initial 
rapid release and subsequent controlled release would maintain the effective concentration of ITZ in PBS for a long time.

\section{Cellular uptake of Coumarin 6 (C6) and Cy3 siRNA co-loaded NPs in 4T1 cells}

After we double labeled the composite nanoparticles (Cy3 siRNA red, C6 Green), confocal laser scanning microscopy (CLSM) was used to visually observe the cellular uptake of ITZ-siRNA ${ }^{\mathrm{VEGF}}$ NPs into 4T1 cells after $4 \mathrm{~h}$ incubation time. Negatively charged siRNA has difficulty crossing the equally negatively charged membrane into the cell. The site action of siRNA is located in the cytoplasm and nanocarriers loading siRNA must deliver encapsulated siRNA to the action site ${ }^{32}$. As shown in Figure $4 \mathrm{~A}$, after transfecting for $4 \mathrm{~h}$, when compared with free Cy3 siRNA or C6, relatively high co-localization spots of green $\mathrm{C} 6$ and red Cy3 siRNA were found in Cy3 siRNA NPs and C6 NPs groups, suggesting that the efficiency of drug delivery to $4 \mathrm{~T} 1$ cells was greatly improved after modification by delivery vectors. In Cy3 siRNA-C6 NPs group, red and green fluorescent generated yellow stains in the cytoplasm (Figure 4A, e), which suggesting that both drugs are efficiently delivered into cells with the help of delivery vectors, and the nanoparticles enter cells most likely by endocytosis mechanism.

Two-color flow cytometry was used to quantify the cellular uptake of various NPs, and similar results were further visualized. Compared to free Cy3 siRNA, both Cy3 siRNA NPs and Cy3 siRNA-C6 NPs groups had the highest mean fluorescence intensity and had significant improvement (*** $p<0.001)$ (Figure 4B). Similarly, from the Figure 4C, we can see that C6 NPs and Cy3 siRNA-C6 NPs groups had the highest mean fluorescence intensity and had significant difference when compared with the free C6 group ( ${ }^{\star \star \star} p<$ 0.001). In both $\mathrm{C} 6$ and Cy3 siRNA channels, the uptake rate in single drug-loaded NPs and double drugsloaded NPs did not have significant differences.

\section{Endosomal escape}

To further investigate whether the co-loaded NPs could escape from endosomes/lysosomes following cell internalization, intracellular fluorescence distribution was also showed by CLSM. After transfecting for $1 \mathrm{~h}$, co-localization spots of green $\mathrm{C} 6$ and red endosomes/lysosomes were found in Figure 5A, and the signals gradually increased at $2 \mathrm{~h}$, suggesting that the released siRNA ${ }^{\mathrm{VEGF}}$-C6 NPs were entrapped within endosomes/lysosomes. At $4 \mathrm{~h}$, the green $\mathrm{C} 6$ gradually began to escape from the red endosomes/lysosomes, until $6 \mathrm{~h}$, most of the $\mathrm{C} 6$ had successfully escaped. In Figure 5B, the red siRNACy5 gradually entered the green endosomes/lysosomes, and the yellow signal was the strongest at $4 \mathrm{~h}$. While much more siRNA ${ }^{\mathrm{Cy} 5}$ dots were gradually separated from green fluorescence after $6 \mathrm{~h}$ incubation, indicating siRNACy5-ITZ NPs could achieve lysosomal escape into cytoplasm at $6 \mathrm{~h}$. These results demonstrated similar endosomal escape ability of two co-loaded drugs, which could support the evidences for that the composite nanoparticles are likely to enter the cell through endocytosis and subsequently escape from the endosomes/lysosomes through the proton sponge effect of PEl under acidic conditions. 


\section{Wound healing assay}

Since cancer cell metastasis is associated with cell migration, we focused on the invasiveness of 4T1 breast cancer cells. The inhibition of tumor cell migration by ITZ-siRNA ${ }^{\mathrm{VEGF}}$ NPs was investigated by wound healing assay. As shown in Figure $6 \mathrm{~A}, 48 \mathrm{~h}$ after transfection, scratches without any treatment almost completely healed, indicating that $4 \mathrm{~T} 1$ cells had the ability to repair scratches through plane migration. In the free siRNA and blank NPs groups, the scratch site basically healed after $48 \mathrm{~h}$. The

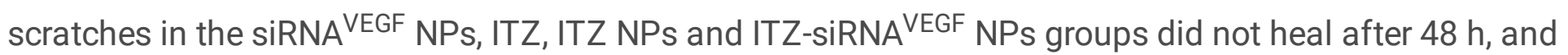
the scratches in the ITZ-siRNA ${ }^{\mathrm{VEGF}}$ NPs group even widened. As a ligand produced by tumor cells and associated stroma, VEGF can activate multiple downstream pathways, results in endothelial cell proliferation and migration ${ }^{33,34}$. Rudin and colleagues ${ }^{35}$ investigated that ITZ could inhibit cell migration, chemotaxis and tube formation on human umbilical vein endothelial cells. In this study, under the combined action of VEGF siRNA and ITZ, the ITZ siRNA VEGF NPs group significantly inhibited the plane migration ability of cells and inhibited cell wound healing, which further confirmed the anticell migration ability of VEGF.

\section{VEGF silencing efficiency and anti-angiogenesis effect of ITZ-siRNAVEGF NPs}

VEGF is considerably expressed in the metastatic stages of cancer, especially breast cancer, so the VEGF promoter can be an appropriate promoter for the transcriptional targeting ${ }^{36}$. ITZ directly ${ }^{8}$ or downregulate VEGF via VEGF siRNA ${ }^{37}$ is a promising strategy for cancer therapy, which can result in the inhibition of tumor angiogenesis and metastasis. Firstly, we investigated whether ITZ-siRNA ${ }^{\text {VEGF }}$ NPs could efficiently knockdown the expression of the therapeutic target gene VEGF with 4T1 breast cancer cell. As shown in Figure 6B, when compared with the untreated control group, there was no significant difference between free siRNA and Blank NPs groups. However, the mRNA expression of siRNA ${ }^{\text {VEGF }}$ NPs and ITZ-siRNA VEGF NPs both exhibited good silencing effects, whereas free VEGF siRNA showed poor suppression because it was difficult to penetrate into the cells and easily degraded in the biological media. Here, siRNA was successfully transfected into cells with the help of PEI-PLA/PEG-PAsp delivery system to achieve silencing effect. Compared with the control group, the expression of VEGF mRNA in ITZ NPs was also decreased, which may be related to the inhibitory effect of ITZ on vascular growth. Studies have shown that ITZ can inhibit the formation of micro vessels, and the possible mechanism is that ITZ inhibits vascular cell growth factors such as VEGF, AAMP and e-nos ${ }^{38}$. Consistent with the above theories, among the results of this experiment, ITZ-siRNA VEGF NPs exhibited the best gene silencing efficiency.

The formation and development of endothelial cell capillary structure is a multistep process, which involving cell adhesion, migration, differentiation and growth ${ }^{37}$. Cancer cells can secrete various inducers into the microenvironment to regulate angiogenesis ${ }^{39}$, we investigated the in vitro antiangiogenesis of HUVEC cells when nanoparticles were directly treated with HUVEC cells and when nanoparticles were cultured with 4T1 cells. Firstly, to assess the direct angiogenetic inhibitory effect of the various 
nanoparticles, HUVECs were co-cultured with the nanoparticles and plated onto Matrigel for $24 \mathrm{~h}$. Compared with the control group (Number of Nodes: $146 \pm 8.54$; Total length: $4881 \pm 136.27$ ), the antitube formation and antiangiogenesis ability of siRNA ${ }^{\text {VEGF }}$, siRNA ${ }^{\text {VEGF }}$ NPs, ITZ, ITZ NPs and ITZsiRNA ${ }^{\text {VEGF }}$ NPs groups was obviously increased, among which, our final preparation group of siRNA ${ }^{\mathrm{VEGF}}$ NPs (Number of Nodes: $0 \pm 0$; Total length: $111 \pm 14$ ) had the highest efficacy, with significant difference $\left({ }^{\star *} p<0.01\right)$. The effect of 4 T1 cells' VEGF downregulation on the endothelial tube formation of HUVECs was also investigated. The conditioned medium treated with different nanoparticles was collected and cultured with HUVECs for $24 \mathrm{~h}$. Similar to the previous experiment, our final preparation group of siRNA ${ }^{V E G F}-I T Z$ NPs had the highest anti-tube formation and antiangiogenesis ability (Number of Nodes: $7.67 \pm 2.08$; Total length: $1124.67 \pm 152.16$ ) on HUVECs after pre-treated with $4 \mathrm{~T} 1$ cells (Figure $6 \mathrm{C}$ (b), 6D, 6E). Consistent with the results of VEGF gene silencing experiment, vector-modified siRNA showed better inhibition efficiency than free siRNA, whether directly acting on HUVECs or after incubation with $4 \mathrm{~T} 1$ cells. In terms of total vessel length, the inhibition effect of siRNAVEGF NPs was even higher than that of free ITZ or ITZ NPs, indicating that VEGF siRNA with the help of the vectors can further successfully inhibit the generation and development of blood vessels in vitro by down-regulating the expression of VEGF-related genes. This result could be attributed to the distinctive performance of the PEI-PLA/PEGPAsp-based delivery system with the excellent enhancement of cellular uptake and gene transfection efficiency as mentioned above.

\section{Cell inhibition and apoptosis analysis}

In order to investigate the effects of ITZ and VEGF siRNA on cell proliferation, CCK-8 method was used to measure the cell inhibition rate of different nanoparticles. As shown in Figure 7A, compared to the control group, cell proliferation inhibitory rates of ITZ, ITZ NPs, and ITZ-siRNA ${ }^{\text {VEGF }}$ NPs treated groups were significantly elevated $(* * p<0.01)$ in both $4 \mathrm{~T} 1$ and A549 cell lines. Within a certain concentration range, ITZ-siRNA VEGF NPS with dual loading showed the highest inhibition rate. For the $4 \mathrm{~T} 1$ cell line, the survival rates of the cells treated with siRNA VEGF NPs and ITZ NPs were $82.27 \% \pm 5.65 \%$ and $55.85 \% \pm$ $4.83 \%$, respectively, while that of cells treated with ITZ-siRNA ${ }^{\text {VEGF }}$ NPs was $51.72 \% \pm 4.62 \%$. And for the A549 cell line, the survival rates of the cells treated with siRNA VEGF NPs and ITZ NPs were $80.59 \% \pm$ $4.32 \%$ and $63.25 \% \pm 6.15 \%$, respectively, while that of cells treated with ITZ-siRNAVEGF NPs was $59.58 \% \pm$ $7.26 \%$ ITZ was reported to induce cancer cell death via apoptosis mainly due to alteration of mitochondria membrane potential, reduction of Bcl-2 expression and increase of caspase-3 activity 9,40 . The greater cytotoxic effect of ITA-loaded NPs as compared to free ITZ against 4T1 cells could be attributed to the small size and rapid uptake of nano-formulations, which facilitates different mechanisms of transport, such as endocytosis or passive transport. We further measured the cell inhibition rate of ITZ NPs and ITZ siRNAVEGF NPs with different ITZ concentrations $(0.05-5 \mu \mathrm{g} / \mathrm{mL})$ by CCK-8 method. In Figure 7B, all formulations displayed a typical dose-dependent cytotoxicity to the 4T1 and $A 549$ cells for $48 \mathrm{~h}$. Free ITZ displayed certain antitumor activity, and this cytotoxicity was enhanced by delivering ITZ and VEGF siRNA using PEI-PLA/PEG-PAsp NPs to enhance cellular accumulation. 
To study the apoptosis effect of ITZ-siRNA ${ }^{\text {VEGF }}$ NPs, we evaluated cell apoptosis post-drug treatment by flow cytometry, using an annexin V/FITC kit. As shown in Figure 7C, 4T1 cells treated with blank NPs (PEIPLA/PEG-PAsp) showed $4.66 \%$ of apoptosis percentage, confirming that the blank polymeric delivery system produced minor effect on normal cell progression. The delivery of VEGF siRNA into 4T1 cells with PEI-PLA/PEG-PAsp NPs led to $12.22 \%$ cell apoptosis, while only $7.75 \%$ cell apoptosis was observed when the cells were treated with free siRNA. Similarly, the apoptosis rate of cells treated with ITZ NPs was increased to $13.72 \%$, while the apoptosis rate of cells treated with free ITZ was $10.99 \%$. However, the dual-loaded ITZ-siRNA ${ }^{\text {VEGF }}$ NPs led to the highest cell apoptosis rate of $14.16 \%$. Previous reports have suggested that ITZ can induce cell death via apoptosis induction in breast cancer cells ${ }^{41}$. Furthermore, it had been reported that VEGF provides a survival signal for breast tumor cells in vitro and blockade of VEGF results in apoptosis of these cells ${ }^{42}$. From the result, it can be speculated that the co-delivery of ITZ and VEGF siRNA activated the intrinsic apoptotic pathway, promoted cell apoptosis and played a synergistic efficacy.

\section{In vivo antitumor efficacy and angiogenesis suppression}

We established an animal model of $4 \mathrm{~T} 1$ breast cancer in situ and investigated the inhibition of ITZsiRNA ${ }^{\mathrm{VEGF}}$ NPs on the growth of tumor and the inhibition of VEGF expression. In Figure $8 \mathrm{~A}$ and $8 \mathrm{C}$, the luminescence intensity of the control group was above $6.5 \times 10^{6} \mathrm{p} / \mathrm{s} / \mathrm{cm}^{2} / \mathrm{Sr}$, and the luminescence intensity was the strongest, followed by the blank nano group, which was above $5.8 \times 10^{6} \mathrm{p} / \mathrm{s} / \mathrm{cm}^{2} / \mathrm{Sr}$. The intensities of ITZ NPs and ITZ-siRNAVEGF NPs were about $2.0 \times 10^{6} \mathrm{p} / \mathrm{s} / \mathrm{cm}^{2} / \mathrm{Sr}$ and $1.7 \times 10^{6}$ $\mathrm{p} / \mathrm{s} / \mathrm{cm}^{2} / \mathrm{Sr}$, respectively, with significant differences when compared with control group (** $\left.\mathrm{P}<0.01\right)$. In figure $8 \mathrm{~B}$ and $8 \mathrm{D}$, the tumor size of control group and blank NPs group continued to increase. It increased from $98.27 \pm 22.57 \mathrm{~mm}^{3}$ and $105.92 \pm 15.80 \mathrm{~mm}^{3}$ to $345.71 \pm 76.88 \mathrm{~mm}^{3}$ and $331.68 \pm 83.27 \mathrm{~mm}^{3}$, respectively. SIRNA ${ }^{\mathrm{VEGF}}$ NPs and ITZ-NPs groups also increased from $97.62 \pm 21.947 \mathrm{~mm}^{3}$ and $106.32 \pm$

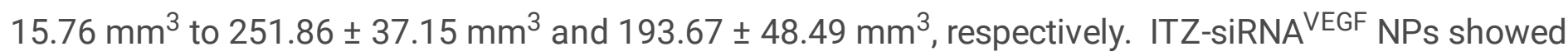
the best tumor inhibition, growing from $106.42 \pm 15.72 \mathrm{~mm}^{3}$ to $142.91 \pm 23.62 \mathrm{~mm}^{3}$, respectively. Accordingly, the weight of tumor tissue in each group showed that the tumor weight in the ITZ-siRNAVEGF NPs group was the lightest (Figure 8E). The growth of tumor volume in mice treated with ITZ-siRNAVEGF NPs was well inhibited, indicating that the antitumor effect of ITZ and VEGF siRNA on 4T1 breast cancer mice was obvious.

The histological examination of the tumor sections for apoptosis and necrosis were carried out after HE and TUNEL staining, as shown in Figure 9A. HE staining results showed that the normal saline and Blank NPs groups had the typical histological features of tumor cells with less necrosis. In the siRNA ${ }^{\text {VEGF NPs }}$ and ITZ NPs groups, extensive focal necrosis of cancer cells and pathological mitosis could be observed, and the ITZ-siRNA ${ }^{\mathrm{VEGF}}$ NPs group showed more extensive necrosis and fragmented nucleus with less viable tumor cells regions. Also in the TUNEL assay (Figure 9A and 9B), $53.26 \pm 7.26 \%$ of apoptotic cells was observed in the co-loaded ITZ-siRNAVEGF NPs group, which was much higher than that in the single- 
loaded groups (siRNA ${ }^{\mathrm{VEGF}}$ NPs: $12.45 \pm 5.11 \%$; ITZ NPs: $22.45 \pm 4.85 \%$ ). The HE and TUNEL stained tumor sections revealed that the co-loaded NPs treatment induced significant cell apoptosis and necrosis of the tumor tissues when compared with the control group, indicating the excellent therapeutic efficacy of ITZ-siRNAVEGF NPs.

Subsequent to in vitro investigations, the anti-angiogenic effect of anti-VEGF and anti-CD31 developed ITZ-siRNA ${ }^{\mathrm{VEGF}}$ NPs was investigated in the $4 \mathrm{~T} 1$ breast cancer-bearing mice to study the in vivo angiogenesis suppression. As shown in Figure 9B, compared with control group (2.10 \pm 0.19$)$ and Blank NPs group (1.91 \pm 0.17$)$, VEGF mRNA relative expression of siRNA ${ }^{\mathrm{VEGF}} \mathrm{NPs}(0.90 \pm 0.18)$, ITZ NPs $(0.83 \pm$ $0.17)$ and ITZ-siRNAVEGF NPs $(0.67 \pm 0.07)$ decreased significantly (** $P<0.01)$. Also,

immunohistochemical results showed that the expression levels of VEGF and CD31 in the ITZ-siRNAVEGF NPs treatment groups were significantly suppressed than those of the control group (Figure 9A and 9B; $\star \star p<0.01)$. CD31 is an endothelial marker for quantifying angiogenesis. The results were consistent with the obtained mRNA expression levels of VEGF and in vitro anti-angiogenesis study. ITZ itself can inhibit mTOR and VEGF2 simultaneously by inhibiting the operation of cholesterol, while VEGF siRNA can directly silence the highly expressed VEGF gene in tumor cells. Through the synergism of these two drugs, the growth of tumor blood vessels can be inhibited, further suppressing the growth and development of tumor. To conclude, ITZ-siRNA ${ }^{\mathrm{VEGF}}$-NPs could reduce VEGF and CD31 expression through the synergistic effect of ITZ and VEGF siRNA and inhibited growth and angiogenesis of breast cancer in vivo.

\section{In vivo safety}

In order to investigate the in vivo toxicity of NPs and vectors, we recorded the changes of body weight and liver function indexes during the experiment. Figure 10A showed that the mice in each experimental group did not show significant weight loss during the drug administration cycle, and there was no significant difference among each group. As it has been reported that ITZ could induce hepatic dysfunction, after 4 consecutive intravenous injections at $10 \mathrm{mg} / \mathrm{kg}$ dose every 3 days and an observation period, we determined serum ALT and AST levels of the mice. As shown in Figure 10B and

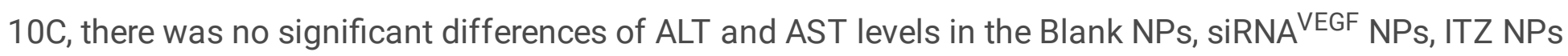

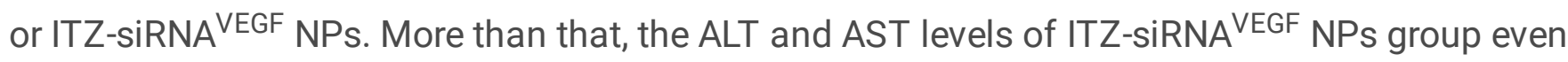
decreased when compared with the control group $\left({ }^{*} p<0.05\right)$. Mice that were implanted with tumor cells caused liver damage, which was recovered after treatment with ITZ-siRNAVEGF NPs, indicating that our nano-delivery systems did not induce liver cytotoxicity in mice. Although ITZ is not the most effective antitumor drug compared to other powerful antitumor drugs, due to its low toxicity and good antiangiogenic anticancer activity ${ }^{8}$, ITZ has been chosen for several clinical trials with cancer patients ${ }^{43}$.

\section{Conclusions}

In conclusion, we have successfully developed a multifunctional pH-sensitive platform for combined tumor chemotherapy and gene therapy using ITZ and VEGF siRNA as model drugs. The prepared 
nanoparticles showed a proper particle size, narrow distribution, weakly positive surface charge, high drug loading, good in vitro stability, and controlled drug release. The carriers-modified nanoparticles showed higher cellular uptake efficacy and gene silencing efficiency than the free drugs. When compared with free drugs or single-loaded nanoparticles, the co-loaded nanoparticles showed highest cytotoxic, apoptotic cell death, anti-angiogenesis effect and anti-migration efficiency in the cancer cell lines. The in vivo results demonstrated that the co-loaded ITZ-siRNAVEGF NPs could inhibit tumor growth effectively due to the combined anti-angiogenesis and anti-tumor effect, as well as low toxicity and little side effects. Overall, our approach is a promising and applicable treatment strategy of nanocarriers for effective targeted anticancer drugs and siRNA drugs. Accordingly, PEI-PLA/PEG-PAsp vectors offer promise as a bioactive nano-platform for the co-delivery of other poorly water-soluble drugs and gene drugs.

\section{Materials And Methods}

\section{Materials, cells and animals}

Poly (lactic acid) with carboxyl groups on one end (PLA-COOH, Mw $=5-15 \mathrm{KDa}$ ) was purchased from Jinan Daigang technology Co., Ltd. Branched polyethyleneimine $\left(\mathrm{Mw}=1.8 \mathrm{KDa}, \mathrm{bPEI}{ }_{1.8 \mathrm{k}}\right)$ was purchased from Alfa Aesar (Ward Hill, MA, USA). Methoxyl-poly (ethylene glycol)-block-poly (L-aspartic acid sodium salt) (PEG-PAsp, $\mathrm{Mw}=6.4 \mathrm{KDa}$ ) was purchased from Alamanda Polymers (USA). 1-(3dimethylaminopropyl)-3-ethylcarbodiimide hydrochloride (EDC) and N-hydroxysuccinimide (NHS) were obtained from Sigma-Aldrich Inc. (Shanghai, China). Itraconazole (ITZ) was purchased from SigmaAldrich Inc. (Shanghai, China). Coumarin-6 (C-6) was purchased from J\&K Scientific. (Beijing, China). RNase A was purchased from Solarbio Ltd. (Beijing, China). TRIzol was purchased from Invitrogen Company (USA). 4', 6-diamidino-2-phenylindole (DAPI) and Hoechst 33258 were bought from the Beyotime Institute of Biotechnology (Jiangsu, China). FITC-Annexin V/PI apoptosis detection kit was purchased from KeyGEN biosciences company (Nanjing, China). BCA protein concentration determination kit (BCA) was purchased from Tiangen Biological Technology Co. (Beijing, China). Trypsin, HEPES buffer, PBS, DMEM and RPMI-1640 media were obtained from Thermo Fisher Scientific Co., Ltd. (Beijing, China). Angiogenesis Assay Kit was purchased from Abcam (ab204726; Shanghai, China). Cell counting kit-8 (CCK-8) was obtained from Dojindo Laboratories (Kumamoto, Japan). SiRNA, targeting VEGF: 5'CGAUGAAGCCCUGGAGUGCdTdT-3' (sense), and negative control siRNA (siNC): 5'UUCUCCGAACGUGUCACGUTT-3' (sense), Cy3 siRNA was purchased from GenePharma Co., Ltd. (Shanghai, China). All other reagents were of analytical grade.

The 4T1 cells were acquired from the Department of Pathology in the Institute of Medicinal Biotechnology at Peking Union Medical College, a stable luciferase transfected cell line (4T1 $1^{\mathrm{Luc}}$ ) was constructed by our laboratory. They were grown in RPMI 1640 media with $10 \%$ fetal bovine serum (FBS) at $37^{\circ} \mathrm{C}$ in $5 \% \mathrm{CO}_{2}$ atmosphere.

The Human Umbilical Vein Endothelial Cells (HUVEC) were acquired from the Department of Pathology in the Institute of Medicinal Biotechnology at Peking Union Medical College. They were grown in DMEM 
media with $10 \%$ fetal bovine serum (FBS), penicillin (IU/ml) and streptomycin $(100 \mu \mathrm{g} / \mathrm{ml})$ at $37^{\circ} \mathrm{C}$ in $5 \%$ $\mathrm{CO}_{2}$ atmosphere.

Female BALB/c nude mice (4-6 weeks old, 18-22 g) were acquired from Vital River Laboratory Animal Technology Co. (Beijing, China). All animal studies were approved by the Laboratory Animal Ethics Committee in the Institute of Materia Medica at the Chinese Academy of Medical Sciences (CAMS) and Peking Union Medical College (PUMC). All the experimental procedures were performed in conformity with institutional guidelines and protocols for the care and use of laboratory animals.

\section{Preparation and evaluation of ITZ-siRNAVEGF NPs}

\section{Preparation of ITZ-siRNAVEGF NPs}

The conjugation of PLA-COOH and $\mathrm{bPEI}_{1.8 \mathrm{k}}$, was synthesized according to the method previously reported by our group ${ }^{4}$. Briefly, $1300 \mathrm{mg}$ of PLA-COOH (1 mmol) was dissolved in DMSO, then EDC $(5 \mathrm{mmol})$ and $\mathrm{NHS}(5 \mathrm{mmol})$ were added and stirred at room temperature for $2 \mathrm{~h}$. $\mathrm{bPEl}_{1.8 \mathrm{k}}(0.33 \mathrm{mmol})$ was added into the dimethyl sulfoxide (DMSO) solution and stirred for another $24 \mathrm{~h}$ in the room temperature. The reacted mixture was dialyzed against $50 \%$ alcohol and distilled water respectively at room temperature for 2 days to remove the extra products. The PEI-PLA copolymer was obtained after freeze-drying. The structure of PEI-PLA was characterized by ${ }^{1} \mathrm{H}$ NMR spectroscopy (Varian Mercury-600 MHz spectrometer, Varian Medical Systems, Inc., Palo Aito, CA, USA) using $\mathrm{D}_{2} \mathrm{O}$ as solvent, and were further confirmed by FTIR (Nicolet 5700, Thermo Inc., USA).

The ITZ-loaded NPs (ITZ NPs) were prepared by dialysis method ${ }^{44}$. ITZ (5 mg) and PEI-PLA (50 mg) dissolved in $2 \mathrm{~mL}$ DMSO were added dropwise to $20 \mathrm{~mL}$ of water under stirring. The mixture was stirred for another $30 \mathrm{~min}$ at room temperature and dialyzed against distilled water using $7 \mathrm{KDa}$ dialysis bag for $24 \mathrm{~h}$. The unentrapped ITZ was removed by filtration through $0.45 \mu \mathrm{m}$ filter (GE Healthcare) and the filtered solution was freeze-dried ${ }^{45}$. For the preparation of VEGF siRNA loaded nanoparticles (siRNAVEGF NPs), PEI-PLA was diluted with distilled water to a certain concentration at N/P ratios (Molar ratio of amino groups of PEl to phosphorus groups of siRNA) of 30, then mixed with equal volume of siRNA solutions (concentration of $2 \mathrm{pmol} / \mu \mathrm{L}$ ). After vortexed for $5 \mathrm{~s}$, the mixture was kept in room temperature for $20 \mathrm{~min}$ to form the siRNA ${ }^{\text {VEGF }}$ NPs. The ITZ and VEGF siRNA co-loaded nanoparticles (ITZ-siRNAVEGF NPs) were prepared in the same way (N/P = 30). Finally, PEG-PAsp was diluted with distilled water to a certain concentration at $\mathrm{C} / \mathrm{N}$ ratio (Molar ratio of carboxyl groups of PEG-PAsp to amino groups of PEIPLA) of 1/5, added to the above prepared solutions. After incubation at room temperature for $20 \mathrm{~min}$, the final nanoparticles were prepared. The particle sizes and zeta potentials of the prepared nanoparticles were measured at $25^{\circ} \mathrm{C}$ using Malvern Zetasizer Nano ZS90 (Malvern instruments Ltd., Worcestershire, UK). The morphology of siRNA ${ }^{\mathrm{VEGF}}$ NPs was observed using transmission electron microscopy (TEM, Hitachi H-7650, Hitachi Ltd., Tokyo, Japan) at voltage of $80 \mathrm{kV}$. 
Determination of drug-loading efficiency (DL) and encapsulation efficiency (EE) in ITZ-siRNAVEGF NPs by HPLC

The following equations were used to calculate the DL and EE. The ITZ concentration was detected by an Agilent 1200 LC (Agilent Tech, USA) HPLC system using an Inertsustain $\mathrm{C}_{18}$ column $(5 \mu \mathrm{m}, 4.6 \mathrm{~mm} \times 250$ $\mathrm{mm})$. The mobile phase consisted of acetonitrile and water $(75: 25, \mathrm{v} / \mathrm{v})$ delivered at a flow rate of 1.0 $\mathrm{mL} / \mathrm{min}$. The injection volume was $20 \mu \mathrm{L}$ and the wavelength was set at $262 \mathrm{~nm}$.

$$
\begin{aligned}
& D L=\frac{\text { Amount of ITZ in NPs }}{\text { Amount of ITZ-loaded NPs }} \times 100 \% 46 \\
& E E=\frac{\text { Amount of } \mathrm{ITZ} \text { in NPs }}{\text { Amount of } \mathrm{ITZ} \text { for loading }} \times 100 \% 47
\end{aligned}
$$

\section{Gel retardation assay of ITZ-siRNAVEGF NPs}

The siRNA association was evaluated by the gel retardation assay on $4 \%$ agarose gel, and the electrophoresis was performed at $120 \mathrm{~V}$ for $20 \mathrm{~min}$. Subsequently, the gel was stained with $0.5 \mathrm{mg} / \mathrm{mL}$ $\mathrm{EtBr}$ for 30 min and photographed under an UV image system (SIM135A, SIMON).

\section{Serum stability of ITZ-siRNAVEGF NPs}

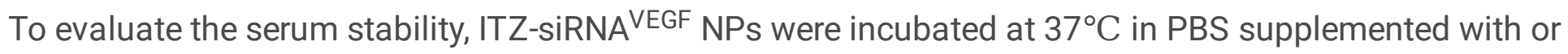
without $10 \%$ fetal bovine serum (FBS), respectively. The average particle sizes of the nanoparticles were monitored by dynamic light scattering (DLS) over a period of $24 \mathrm{~h}$. Each sample was performed in triplicate.

\section{In vitro pH-sensitive ability of ITZ-siRNAVEGF NPs}

For the pH-sensitive analysis, the ITZ-siRNA VEGF NPs were kept in $10 \mathrm{nM} \mathrm{HEPES} \mathrm{buffer} \mathrm{of} \mathrm{different} \mathrm{pH}$ values, respectively. Then, the particle sizes and zeta potentials of the co-loaded NPs were measured at $25^{\circ} \mathrm{C}$ using Malvern Zetasizer Nano ZS90 (Malvern instruments Ltd., Worcestershire, UK).

In vitro $\mathrm{pH}$-sensitive release of ITZ in different formulations was evaluated using dialysis diffusion technique. The release study was carried in PBS ( $\mathrm{pH} 5.5$ and $\mathrm{pH} 7.4)$ containing sodium lauryl sulphate $\left(0.5 \%, w / v\right.$ solution), up to $72 \mathrm{~h}$ as per the reported methods ${ }^{48}$. Each sample of $0.5 \mathrm{~mL}$ NPs containing $0.3 \mathrm{mg}$ ITZ was added into a dialysis bag $(7 \mathrm{KDa})$ and tightly sealed. Then the bags were immersed in 40 $\mathrm{mL}$ PBS solution, incubated in an orbital shaker at $37^{\circ} \mathrm{C}$. At predetermined time points, $0.2 \mathrm{~mL}$ of each sample was withdrawn from the medium and the same volume of fresh medium was added. Each sample was centrifuged at $10000 \mathrm{r} / \mathrm{min}$ and the supernatant was assayed by HPLC.

\section{In vitro cellular experiments}




\section{Confocal laser scanning microscopy analysis}

To assess the cellular uptake and endosomal escape of the nanoparticles, confocal laser scanning microscopy (CLSM) was used. 4T1 cells were seeded onto coverslips in a 12-well plate at a density of $5 \times 10^{4}$ cells per well and incubated at $37^{\circ} \mathrm{C}$ to allow cell attachment. After $24 \mathrm{~h}$, the medium was replaced with serum-free cell culture containing various formulations of NPs (N/P $=30, C / N=1 / 5 ; C-6$ : $0.1 \mu \mathrm{g} / \mathrm{mL}$ ) at $50 \mathrm{nM}$ siRNA per well for $4 \mathrm{~h}$. After washed with cold PBS, cells were fixed with $4 \%$ paraformaldehyde for $15 \mathrm{~min}$. DAPI was subsequently added to stain nuclei. Finally, the sample was observed and imaged on a confocal microscope (Carl Zeiss LSM 710, Carl Zeiss Microscopy GmbH, Germany).

For endosomal escape investigation, $24 \mathrm{~h}$ cultured $4 \mathrm{~T} 1$ cells on petri dish were cultured with siRNA ${ }^{\mathrm{VEGF}}$ C6 NPs and siRNACy5-ITZ NPs for $1 \mathrm{~h}, 2 \mathrm{~h}, 4 \mathrm{~h}$ and $6 \mathrm{~h}$ respectively. The concentration of $\mathrm{C} 6$ and FAM siRNA was $1 \mu \mathrm{M}$ and $100 \mathrm{nM}$, respectively. Then, the endosome was stained with Lyso-Tracker Red and LysoTracker Green at $37{ }^{\circ} \mathrm{C}$ for $30 \mathrm{~min}$. Subsequently, the cells were rinsed with cold PBS, fixed with $4 \%(\mathrm{w} / \mathrm{v})$ formaldehyde and stained with DAPI. After washing away the residual dye, the endosome escape of the nanoparticles was observed on CLSM.

\section{Quantitative cell uptake study}

To qualitatively evaluate the cellular uptake of co-loaded nanoparticles, they were labeled with Cy3 siRNA and C6. 4T1 cells were seeded into a 12-well plate at a density of $5 \times 10^{4}$ cells per well and incubated at 37 ${ }^{\circ} \mathrm{C}$ to allow cell attachment. After $24 \mathrm{~h}$, the medium was replaced with serum-free cell culture medium containing various formulations of NPs $(N / P=30, C / N=1 / 5 ; C 6: 0.5 \mu M)$ at $50 \mathrm{nM}$ siRNA per well for $4 \mathrm{~h}$. For the flow cytometry analysis, the cells were washed three times with PBS buffer and trypsinized, the harvested cells were resuspended in the fresh medium and washed with cold PBS. Finally, the cells were resuspended in $0.5 \mathrm{~mL}$ PBS buffer and analyzed with FACSCalibur flow cytometer (Becton Dickinson, Franklin Lake, NJ, USA).

\section{Wound healing assay}

4T1 cells were seeded into a 12-well plate at a density of $5 \times 10^{4}$ cells per well for $24 \mathrm{~h}$. Then the confluent cell monolayer per well was wounded with a $200 \mu \mathrm{L}$ pipette tip, washed with serum-free medium and exposed to different formulations (PBS, siRNA VEGF, ITZ, blank NPs, siRNA ${ }^{\mathrm{VEGF}}$ NPs, ITZ NPs and ITZsiRNA $^{\mathrm{VEGF}} \mathrm{NPs}(\mathrm{N} / \mathrm{P}=30 ; \mathrm{C} / \mathrm{N}=1 / 5$; ITZ content: $8.28 \% ; 100 \mathrm{nM}$ of siRNA/each well)), cells untreated were used as controls. Medium per well was replaced with fresh complete medium after $4 \mathrm{~h}$ incubation. The healing status of scratch wound were observed and imaged during the next culture time.

\section{In vitro gene silencing efficiency assay}

To test the siRNA silencing efficacy on VEGF expression, 4T1 cells were incubated into a 6-well plate at a density of $1 \times 10^{5}$ cells per well for $24 \mathrm{~h}$. Then the cells were incubated in $2 \mathrm{~mL}$ of serum-free RPMI 1640 
medium containing different nanoparticles for $4 \mathrm{~h}$. The final siRNA concentration was $100 \mathrm{nM}$ in each well, and in order to avoid the toxic interference brought by ITZ, the content of ITZ in each formulation was controlled below $2 \mathrm{nM}$. After $4 \mathrm{~h}$ incubation, the transfection medium in each well was replaced by fresh medium containing $10 \%$ FBS, and incubated for another $20 \mathrm{~h}$. Finally, the total RNA was extracted from the cells with TRIzol Reagent (Invitrogen), then transcribed to cDNA using ReverAid First Strand cDNA Synthesis kit (Fermentas). The mRNA levels of the target genes were quantified by real time PCR using SYBR Green qPCR kit (Takara Biotechnology Co., Ltd., Dalian, China) along with the selected DNA primer pairs. Primer pairs used were VEGF (forward, 5'-GAAGACACGGTGGTGGAAGAAGAG-3'; reverse, 5'GGGAAGGGAAGATGAGGAAGGGTA-3') and GAPDH (forward, 5'-GAGCCAAAAGGGTCATCATCT-3'; reverse, $5^{\prime}$-AGGGGCCATCCACAGTCTTC-3'). All the results were expressed as $x \pm s$ of 3 measurements.

\section{In vitro angiogenesis and tube formation}

In vitro angiogenesis and tube formation assays were conducted to evaluate the ability of tubular formation of endothelial cells after treatment ${ }^{17,37}$. Briefly, $50 \mu \mathrm{L}$ of liquefied Matrigel was placed in 96 well plates and incubated in $37^{\circ} \mathrm{C}$ for $30 \mathrm{~min}$. HUVEC cells in DMEM medium alone or with the various formulations of NPs (N/P = 30, C/N = 1/5; ITZ: 8.28\%) at $100 \mathrm{nM}$ VEGF siRNA were seeded onto the surface of the Matrigel at a final density of $1 \times 10^{4}$ cells per well for $18 \mathrm{~h}$ in a $37^{\circ} \mathrm{C}$ incubator containing $5 \% \mathrm{CO}_{2}$.

To investigate 4T1-related endothelial tube formation and angiogenesis efficiency, the 4T1 cells were seeded into 6-well plates and cultured for $24 \mathrm{~h}$ at a density of $1 \times 10^{4}$ cells per well ${ }^{39}$. Then, the cells were treated and transfected with different formulations of NPs (N/P = 30, C/N = 1/5; ITZ: 8.28\%) at $100 \mathrm{nM}$ VEGF siRNA and cultured for 24h. Their media were called "conditioned medium". Subsequently, HUVEC cells in "conditioned medium" were seeded onto the surface of the Matrigel at a final density of $1 \times 10^{4}$ cells per well for $18 \mathrm{~h}$ in a $37^{\circ} \mathrm{C}$ incubator containing $5 \% \mathrm{CO}_{2}$. Final pictures were captured via IX51 inverted fluorescence microscope (Olympus Corporation, Tokyo, Japan).

\section{Inhibition of the effect of ITZ-siRNAVEGF NPs in cell proliferation}

4T1 cells were seeded in 96-well plates at the density of $3 \times 10^{3}$ cells per well and incubated for $24 \mathrm{~h}$ to allow cell attachment. Naked siRNA (siRNA ${ }^{\mathrm{VEGF}}$ ), ITZ, blank NPs (PEI-PLA/PEG-PAsp), siRNA VEGF NPs, ITZ NPs and ITZ-siRNAVEGF NPs (N/P = 30; C/N = 1/5; ITZ content: $8.28 \%$ ) were added to the cells and incubated for $72 \mathrm{~h}$. The final siRNA concentration was $20 \mathrm{nM}$ in each well, and the optical density (OD) was measured at $450 \mathrm{~nm}$ using the Synergy $\mathrm{H} 1 \mathrm{~m}$ Monochromator-Based Multi-Mode Microplate Reader (BioTek., USA). Untreated cells were taken as control with $100 \%$ of viability. The results were expressed as $\mathrm{x} \pm \mathrm{s}$ of 4 measurements.

To study the cytotoxicity of ITZ, ITZ NPs and ITZ-siRNAVEGF NPs, A549 cells and 4T1 cells were seeded at $5 \times 10^{3}$ cells/well plate. After overnight incubation, the medium was replaced with fresh medium containing different concentrations of ITZ $(0.05 \sim 5 \mu \mathrm{g} / \mathrm{mL})$ or siRNA (20 nm per well) for $48 \mathrm{~h}$. After the 
incubation, $10 \mu \mathrm{L}$ of CCK-8 reagent was added to each well, cultured for $3 \mathrm{~h}$, and the absorbance value of each well was measured at $450 \mathrm{~nm}$. Untreated cells served as controls with $100 \%$ viability.

\section{Cell apoptosis study}

4T1 cells were seeded into a 12-well plate at a density of $5 \times 10^{4}$ cells per well, treated with PBS, siRNA $^{\text {VEGF }}$, ITZ, blank NPs, siRNA ${ }^{\text {VEGF }}$ NPs, ITZ NPs and ITZ-siRNA ${ }^{\text {VEGF }}$ NPs (N/P = 30; C/N = 1/5; ITZ content: $8.28 \% ; 50 \mathrm{nM}$ of siRNA/each well) for $24 \mathrm{~h}$. For quantitative measurement of apoptosis, the cells were harvested by $0.25 \%$ trypsin without EDTA, washed with PBS, resuspended in binding buffer, and stained with Annexin V-FITC/PI for 15 min, then analyzed by FACSCalibur flow cytometer.

\section{In vivo anticancer efficacy}

\section{In vivo inhibitory effect of ITZ-siRNAVEGF NPs on breast cancer}

Female BALB/c mice (4-6 weeks old, 18-22 g) were acquired from Vital River Laboratory Animal Technology Co., Ltd. (Beijing, China). The animal experiment was ethically approved by Laboratory Animal Ethics Committee in the Institute of Materia Medica in Peking Union Medical College. All the experimental procedures were performed in conformity with institutional guidelines and protocols for the care and use of laboratory animals.

$1 \times 10^{5} 4 \mathrm{~T} 1^{\text {Luc }}$ cells were orthotopically inoculated in the fourth mammary fat pad in the right lower abdomen of 4-6 weeks old female BALB/c mice. When the tumor volume reached around $130 \mathrm{~mm}^{3}$, tumor-bearing mice were randomly assigned into five groups ( $n=4 /$ group). The mice were injected with the following preparations respectively: saline, blank NPs, siRNAVEGF NPs, ITZ NPs and ITZ-siRNAVEGF NPs. ITZ was administered at a dose of $10 \mathrm{mg} / \mathrm{kg}$, and VEGF siRNA was administered at a dose of 3 $\mathrm{mg} / \mathrm{kg}$. All the formulations were given to mice via tail vein every 3 days for 4 times, and the tumor volumes were measured each 2 days $(n=4)$. After the final administration, $0.1 \mathrm{~mL}$ Luciferin $(10 \mathrm{mg} / \mathrm{mL})$ was intraperitoneally injected, and the mice were anesthetized with 1-2\% isoflurane for 10-15 min. Then the mice were fixed in the Xenogen in vivo imaging system to detect tumor bioluminescence. During the experiment, body weights and tumor sizes of the mice were determined.

\section{Detection of VEGF and CD31 expression in tumor tissues}

Two weeks after the last administration, mice were euthanized by cervical dislocation after which tumor tissues were resected and fixed in $4 \%$ neutral formaldehyde solution for $72 \mathrm{~h}$ and subjected to VEGF mRNA expression. For the immunohistochemical analysis, the tumor sections were fixed with $4 \%$ neutral formaldehyde, and were incubated with a monoclonal rabbit polyclonal anti-VEGF antibody (1:250) and anti-CD31 antibody (Abcam, Cambridge, UK, ab28364) at $4^{\circ} \mathrm{C}$ overnight, respectively. The secondary antibody (goat antirabbit IgG-HRP) (Cell Signaling Technologies) was applied (1:1000) and incubated for $45 \mathrm{~min}$ at room temperature. The sections were visualized and photographed under a light microscope. 


\section{In vivo safety evaluation}

Two weeks after the last administration, blood samples were collected from the orbit, alanine aminotransferase (ALT) and aspartate aminotransferase (AST) levels were measured to evaluate drug toxicity in mice.

\section{Statistical analysis}

Data are presented as mean \pm standard deviation (SD). Significant differences between two groups were evaluated using the student's t-test. Comparisons among multiple groups were performed by one-way analysis of variance (ANOVA) with Bonferroni's post hoc test.

\section{Declarations}

Funding: This work was financially supported by National Natural Science Fund of China (82104106, 82073778).

Acknowledgments: This work was supported by Beijing Key Laboratory of Drug Delivery Technology and Novel Formulations, Institute of Materia Medica, Chinese Academy of Medical Sciences and Peking Union Medical College.

Conflict of Interest: The authors declare no conflict of interest.

\section{References}

1. Chitkara, D.; Singh, S.; Mittal, A., Nanocarrier-based co-delivery of small molecules and siRNA/miRNA for treatment of cancer. Ther Deliv 2016, 7(4), 245-55.

2. Guan, X.; Li, Y.; Jiao, Z.; Lin, L.; Chen, J.; Guo, Z.; Tian, H.; Chen, X., Codelivery of antitumor drug and gene by a pH-sensitive charge-conversion system. ACS Appl Mater Interfaces 2015, 7(5), 3207-15.

3. Xiao, B.; Ma, L.; Merlin, D., Nanoparticle-mediated co-delivery of chemotherapeutic agent and siRNA for combination cancer therapy. Expert Opin Drug Deliv 2017, 14 (1), 65-73.

4. Jin, M.; Jin, G.; Kang, L.; Chen, L.; Gao, Z.; Huang, W., Smart polymeric nanoparticles with pHresponsive and PEG-detachable properties for co-delivering paclitaxel and survivin siRNA to enhance antitumor outcomes. Int J Nanomedicine 2018, 13, 2405-2426.

5. Jin, M.; Hou, Y.; Quan, X.; Chen, L.; Gao, Z.; Huang, W., Smart Polymeric Nanoparticles with pHResponsive and PEG-Detachable Properties (II): Co-Delivery of Paclitaxel and VEGF siRNA for Synergistic Breast Cancer Therapy in Mice. Int J Nanomedicine 2021, 16, 5479-5494.

6. Tsubamoto, H.; Ueda, T.; Inoue, K.; Sakata, K.; Shibahara, H.; Sonoda, T., Repurposing itraconazole as an anticancer agent. Oncol Lett 2017, 14 (2), 1240-1246.

7. Vanden Bossche, H.; Marichal, P.; Gorrens, J.; Geerts, H.; Janssen, P. A., Mode of action studies. Basis for the search of new antifungal drugs. Ann NY Acad Sci 1988, 544, 191-207. 
8. Aftab, B. T.; Dobromilskaya, I.; Liu, J. O.; Rudin, C. M., Itraconazole inhibits angiogenesis and tumor growth in non-small cell lung cancer. Cancer Res 2011, 71 (21), 6764-72.

9. Wang, X.; Wei, S.; Zhao, Y.; Shi, C.; Liu, P.; Zhang, C.; Lei, Y.; Zhang, B.; Bai, B.; Huang, Y.; Zhang, H., Antiproliferation of breast cancer cells with itraconazole: Hedgehog pathway inhibition induces apoptosis and autophagic cell death. Cancer Lett 2017, 385, 128-136.

10. Chong, C. R.; Xu, J.; Lu, J.; Bhat, S.; Sullivan, D. J., Jr.; Liu, J. O., Inhibition of angiogenesis by the antifungal drug itraconazole. ACS Chem Bio/ 2007, 2 (4), 263-70.

11. Vanden Bossche, H.; Marichal, P.; Le Jeune, L.; Coene, M. C.; Gorrens, J.; Cools, W., Effects of itraconazole on cytochrome P-450-dependent sterol 14 alpha-demethylation and reduction of 3ketosteroids in Cryptococcus neoformans. Antimicrob Agents Chemother 1993, 37 (10), 2101-5.

12. Ellis, L. M.; Hicklin, D. J., VEGF-targeted therapy: mechanisms of anti-tumour activity. Nat Rev Cancer 2008, 8 (8), 579-91.

13. Carmeliet, P.; Jain, R. K., Molecular mechanisms and clinical applications of angiogenesis. Nature 2011, 473 (7347), 298-307.

14. Leite de Oliveira, R.; Hamm, A.; Mazzone, M., Growing tumor vessels: more than one way to skin a cat - implications for angiogenesis targeted cancer therapies. Mol Aspects Med 2011, 32 (2), 71-87.

15. Resnier, P.; Montier, T.; Mathieu, V.; Benoit, J. P.; Passirani, C., A review of the current status of siRNA nanomedicines in the treatment of cancer. Biomaterials 2013, 34 (27), 6429-43.

16. Sarsons, C. D.; Tekrony, A.; Yaehne, K.; Childs, S.; Rinker, K. D.; Cramb, D., Testing nanoparticles for angiogenesis-related disease: charting the fastest route to the clinic. J Biomed Nanotechno/ 2014, 10 (9), 1641-76.

17. Okeke, C. I.; Eltahan, A. S.; Zhang, T.; Chen, J.; Wang, Y.; Xu, M. Q.; Liu, L.; Yang, A. Q.; Guo, W.; Liang, X. J., Co-Delivery of Itraconazole and Docetaxel by Core/Shell Lipid Nanocells for Systemic Antiangiogenesis and Tumor Growth Inhibition. J Biomed Nanotechnol 2017, 13 (11), 1398-1412.

18. Hanahan, D.; Weinberg, R. A., Hallmarks of cancer: the next generation. Cell 2011, 144 (5), 646-74.

19. Fakhrejahani, E.; Toi, M., Antiangiogenesis therapy for breast cancer: an update and perspectives from clinical trials. Jpn J Clin Oncol 2014, 44 (3), 197-207.

20. Nacev, B. A.; Grassi, P.; Dell, A.; Haslam, S. M.; Liu, J. O., The antifungal drug itraconazole inhibits vascular endothelial growth factor receptor 2 (VEGFR2) glycosylation, trafficking, and signaling in endothelial cells. J Biol Chem 2011, 286 (51), 44045-44056.

21. Hara, M.; Nagasaki, T.; Shiga, K.; Takeyama, H., Suppression of Cancer-associated Fibroblasts and Endothelial Cells by Itraconazole in Bevacizumab-resistant Gastrointestinal Cancer. Anticancer Res 2016, 36 (1), 169-77.

22. Pannu, J.; McCarthy, A.; Martin, A.; Hamouda, T.; Ciotti, S.; Fothergill, A.; Sutcliffe, J., NB-002, a novel nanoemulsion with broad antifungal activity against dermatophytes, other filamentous fungi, and Candida albicans. Antimicrob Agents Chemother 2009, 53 (8), 3273-9. 
23. Peeters, J.; Neeskens, P.; Tollenaere, J. P.; Van Remoortere, P.; Brewster, M. E., Characterization of the interaction of 2-hydroxypropyl-beta-cyclodextrin with itraconazole at pH 2, 4, and 7. J Pharm Sci 2002, 91 (6), 1414-22.

24. Ding, X.; Wang, W.; Wang, Y.; Bao, X.; Wang, Y.; Wang, C.; Chen, J.; Zhang, F.; Zhou, J., Versatile reticular polyethylenimine derivative-mediated targeted drug and gene codelivery for tumor therapy. Mol Pharm 2014, 11 (10), 3307-21.

25. Alhakamy, N. A.; Md, S., Repurposing Itraconazole Loaded PLGA Nanoparticles for Improved Antitumor Efficacy in Non-Small Cell Lung Cancers. Pharmaceutics 2019, 11 (12).

26. Parveen, S.; Sahoo, S. K., Long circulating chitosan/PEG blended PLGA nanoparticle for tumor drug delivery. Eur J Pharmacol 2011, 670 (2-3), 372-83.

27. Lo, J. H.; Kwon, E. J.; Zhang, A. Q.; Singhal, P.; Bhatia, S. N., Comparison of Modular PEG Incorporation Strategies for Stabilization of Peptide-siRNA Nanocomplexes. Bioconjug Chem 2016, $27(10), 2323-2331$.

28. Yi, Y.; Yoon, H. J.; Kim, B. O.; Shim, M.; Kim, S. O.; Hwang, S. J.; Seo, M. H., A mixed polymeric micellar formulation of itraconazole: Characteristics, toxicity and pharmacokinetics. J Control Release 2007, $177(1), 59-67$.

29. Zhang, L.; Liu, Z.; Yang, K.; Kong, C.; Liu, C.; Chen, H.; Huang, J.; Qian, F., Tumor Progression of NonSmall Cell Lung Cancer Controlled by Albumin and Micellar Nanoparticles of Itraconazole, a Multitarget Angiogenesis Inhibitor. Mol Pharm 2017, 14 (12), 4705-4713.

30. Cao, N.; Cheng, D.; Zou, S.; Ai, H.; Gao, J.; Shuai, X., The synergistic effect of hierarchical assemblies of siRNA and chemotherapeutic drugs co-delivered into hepatic cancer cells. Biomaterials 2011, 32 (8), 2222-32.

31. Yuan, X.; Shah, B. A.; Kotadia, N. K.; Li, J.; Gu, H.; Wu, Z., The development and mechanism studies of cationic chitosan-modified biodegradable PLGA nanoparticles for efficient siRNA drug delivery. Pharm Res 2010, $27(7)$, 1285-95.

32. Takemoto, H.; Nishiyama, N., Functional polymer-based siRNA delivery carrier that recognizes sitespecific biosignals. J Control Release 2017, 267, 90-99.

33. Ohta, Y.; Endo, Y.; Tanaka, M.; Shimizu, J.; Oda, M.; Hayashi, Y.; Watanabe, Y.; Sasaki, T., Significance of vascular endothelial growth factor messenger RNA expression in primary lung cancer. Clin Cancer Res 1996, 2 (8), 1411-6.

34. Ferrara, N., Vascular endothelial growth factor: basic science and clinical progress. Endocr Rev 2004, $25(4), 581-611$.

35. Kelleher, F. C.; Cain, J. E.; Healy, J. M.; Watkins, D. N.; Thomas, D. M., Prevailing importance of the hedgehog signaling pathway and the potential for treatment advancement in sarcoma. Pharmacol Ther 2012, $136(2), 153-68$.

36. Lu, Y.; Madu, C.; Masters, J.; Lu, A.; Li, L., Development of a Novel Anti-HIF-1alpha Screening System Coupled with Biochemical and Biological Validation for Rapidly Selecting Potent Anti-Cancer Compounds. J Cancer 2014, 5 (6), 417-24. 
37. Ding, X.; Su, Y.; Wang, C.; Zhang, F.; Chen, K.; Wang, Y.; Li, M.; Wang, W., Synergistic Suppression of Tumor Angiogenesis by the Co-delivering of Vascular Endothelial Growth Factor Targeted siRNA and Candesartan Mediated by Functionalized Carbon Nanovectors. ACS Appl Mater Interfaces 2017, 9 (28), 23353-23369.

38. Del Carratore, R.; Carpi, A.; Beffy, P.; Lubrano, V.; Giorgetti, L.; Maserti, B. E.; Carluccio, M. A.; Simili, M.; lervasi, G.; Balzan, S., Itraconazole inhibits HMEC-1 angiogenesis. Biomed Pharmacother 2012, 66 (4), 312-7.

39. Tang, Y.; Jia, C.; Wang, Y.; Wan, W.; Li, H.; Huang, G.; Zhang, X., Lactate Consumption via Cascaded Enzymes Combined VEGF siRNA for Synergistic Anti-Proliferation and Anti-Angiogenesis Therapy of Tumors. Adv Healthc Mater 2021, 10 (19), e2100799.

40. El-Sheridy, N. A.; El-Moslemany, R. M.; Ramadan, A. A.; Helmy, M. W.; El-Khordagui, L. K., Enhancing the in vitro and in vivo activity of itraconazole against breast cancer using miltefosine-modified lipid nanocapsules. Drug Deliv 2021, 28 (1), 906-919.

41. Yang, X.; Zhao, L.; Zhang, T.; Xi, J.; Liu, S.; Ren, L.; Zheng, Y.; Zhang, H., Protosappanin B promotes apoptosis and causes G1 cell cycle arrest in human bladder cancer cells. Sci Rep 2019, 9 (1), 1048.

42. Bachelder, R. E.; Crago, A.; Chung, J.; Wendt, M. A.; Shaw, L. M.; Robinson, G.; Mercurio, A. M., Vascular endothelial growth factor is an autocrine survival factor for neuropilin-expressing breast carcinoma cells. Cancer Res 2001, 61 (15), 5736-40.

43. Bae, S. H.; Park, J. H.; Choi, H. G.; Kim, H.; Kim, S. H., Imidazole Antifungal Drugs Inhibit the Cell Proliferation and Invasion of Human Breast Cancer Cells. Biomol Ther (Seoul) 2018, 26 (5), 494-502.

44. Tang, S.; Yin, Q.; Su, J.; Sun, H.; Meng, Q.; Chen, Y.; Chen, L.; Huang, Y.; Gu, W.; Xu, M.; Yu, H.; Zhang, Z.; $\mathrm{Li}, \mathrm{Y}$., Inhibition of metastasis and growth of breast cancer by $\mathrm{pH}$-sensitive poly (beta-amino ester) nanoparticles co-delivering two siRNA and paclitaxel. Biomaterials 2015, 48, 1-15.

45. Navarro, G.; Sawant, R. R.; Biswas, S.; Essex, S.; Tros de llarduya, C.; Torchilin, V. P., P-glycoprotein silencing with siRNA delivered by DOPE-modified PEl overcomes doxorubicin resistance in breast cancer cells. Nanomedicine (Lond) 2012, 7 (1), 65-78.

46. Michaud, L. B.; Valero, V.; Hortobagyi, G., Risks and benefits of taxanes in breast and ovarian cancer. Drug Saf 2000, 23 (5), 401-28.

47. Lee, J.; Lee, S. C.; Acharya, G.; Chang, C. J.; Park, K., Hydrotropic solubilization of paclitaxel: analysis of chemical structures for hydrotropic property. Pharm Res 2003, 20 (7), 1022-30.

48. Alhowyan, A. A.; Altamimi, M. A.; Kalam, M. A.; Khan, A. A.; Badran, M.; Binkhathlan, Z.; Alkholief, M.; Alshamsan, A., Antifungal efficacy of Itraconazole loaded PLGA-nanoparticles stabilized by vitamin-E TPGS: In vitro and ex vivo studies. J Microbiol Methods 2019, 161, 87-95.

\section{Figures}


a
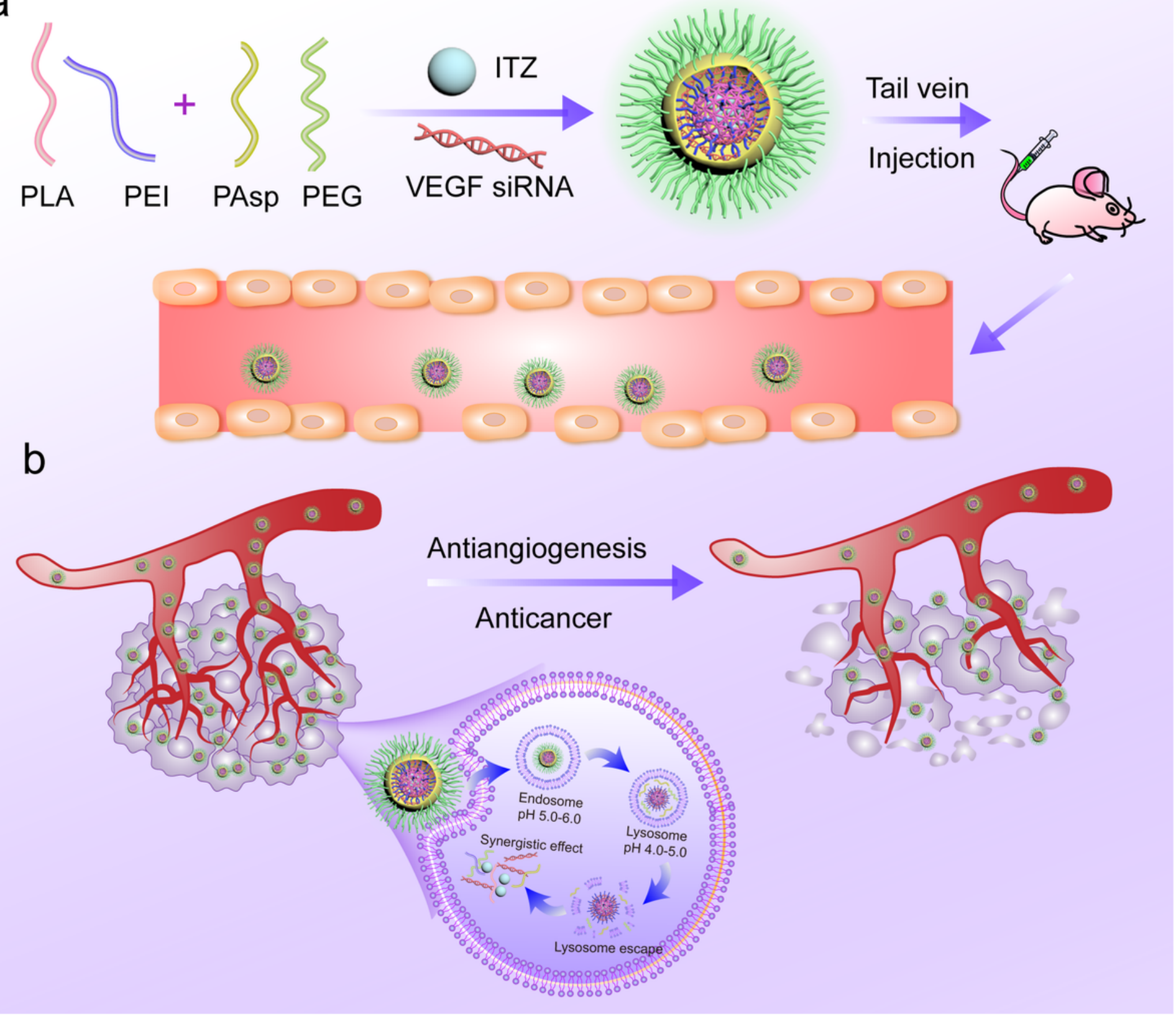

Figure 1

ITZ-siRNA VEGF loaded composite nanoparticle delivery system; (B) Schematic of the intracellular therapeutic mechanism of the ITZ-siRNA ${ }^{\mathrm{VEGF}}$ composite nanoparticles. 
(A)

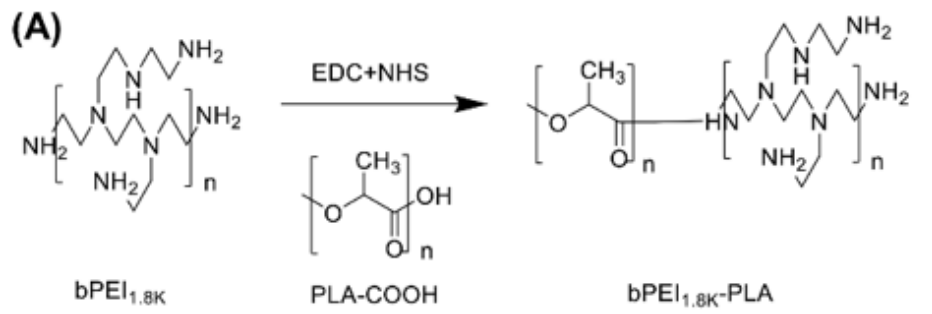

(B)
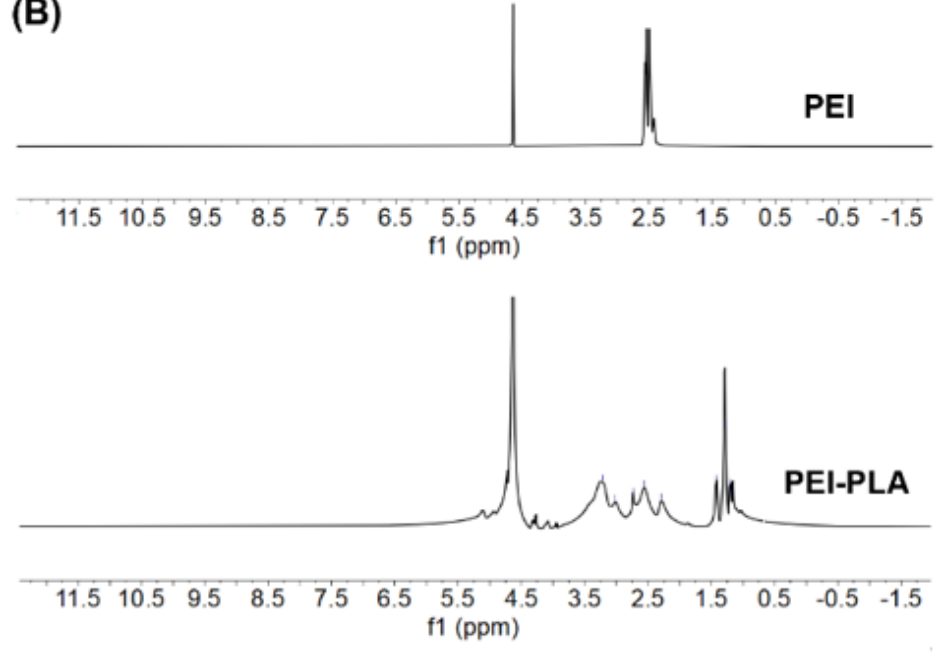

(C)
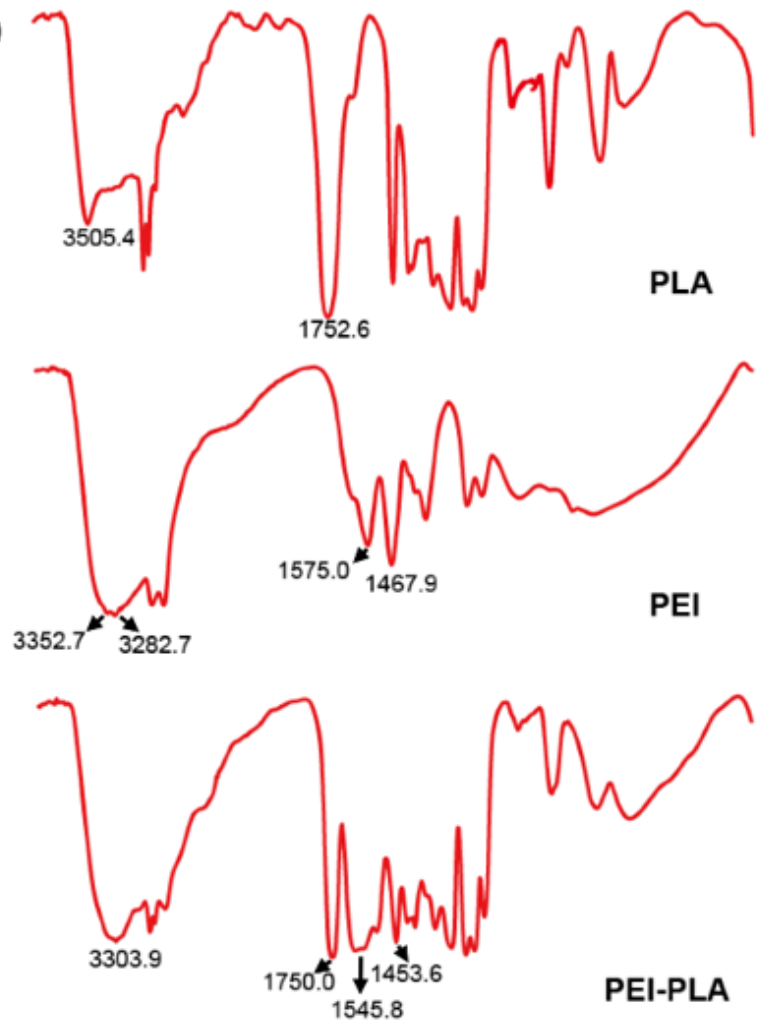

Figure 2

(A) Synthesis of PEI-PLA; (B) ${ }^{1} \mathrm{H}-\mathrm{NMR}$ spectra of PEI and PEI-PLA; (C) FTIR spectra of PLA-COOH and PEIPLA. 
(A)
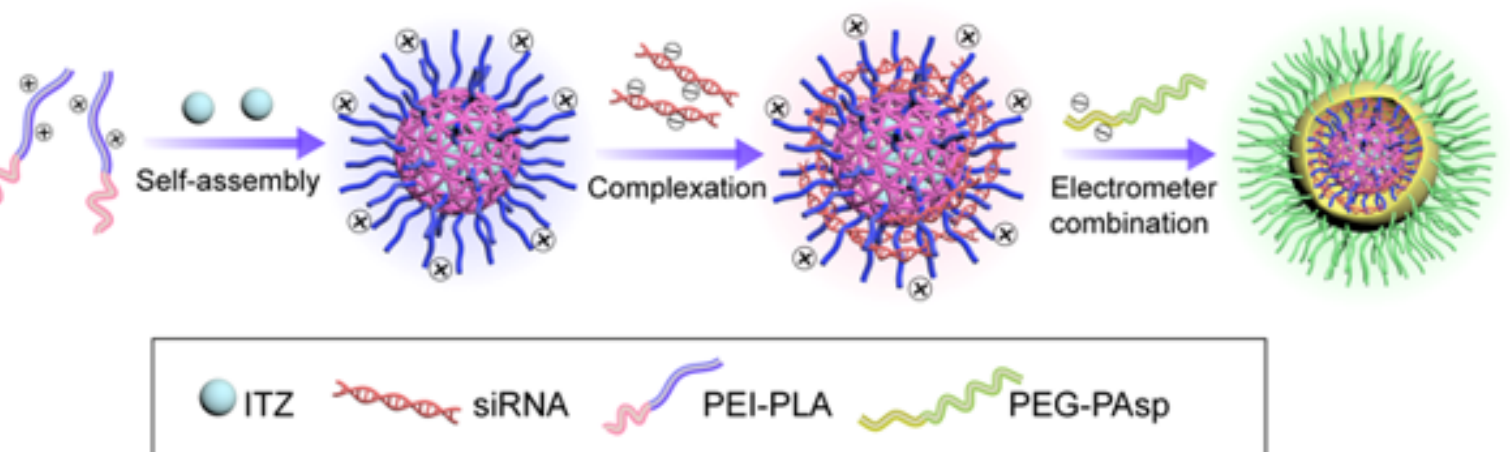

(B)
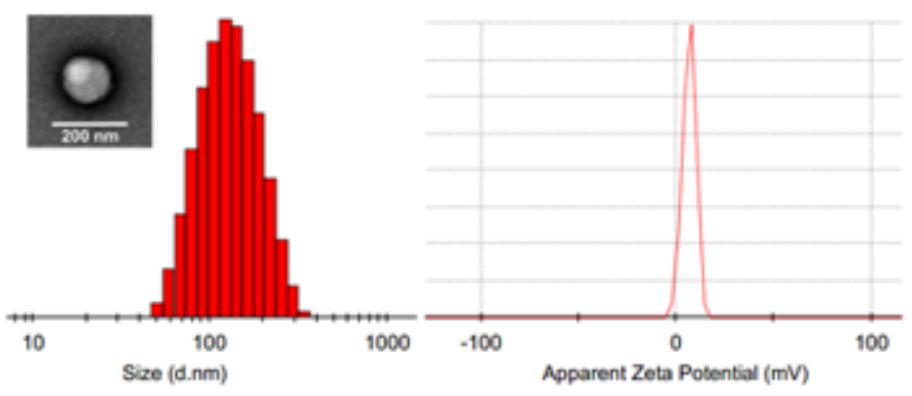

(C) SiRNA 12

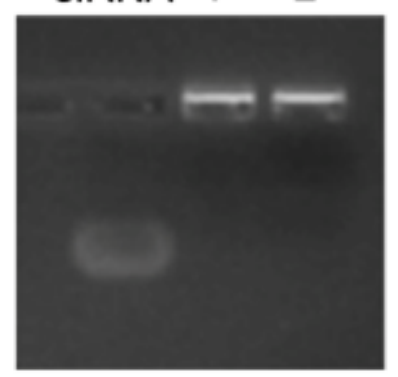

(D)

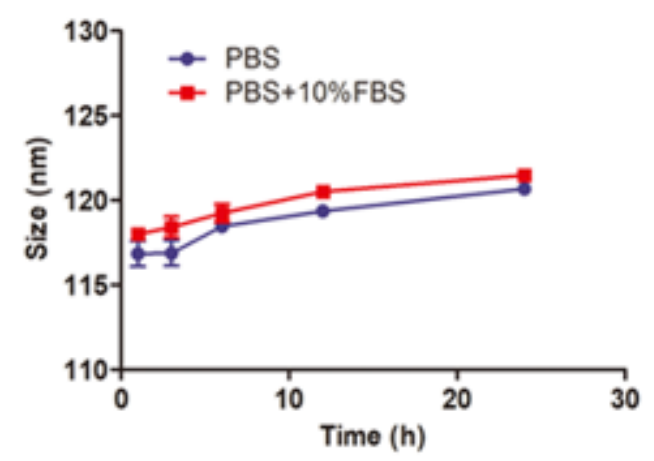

(E)

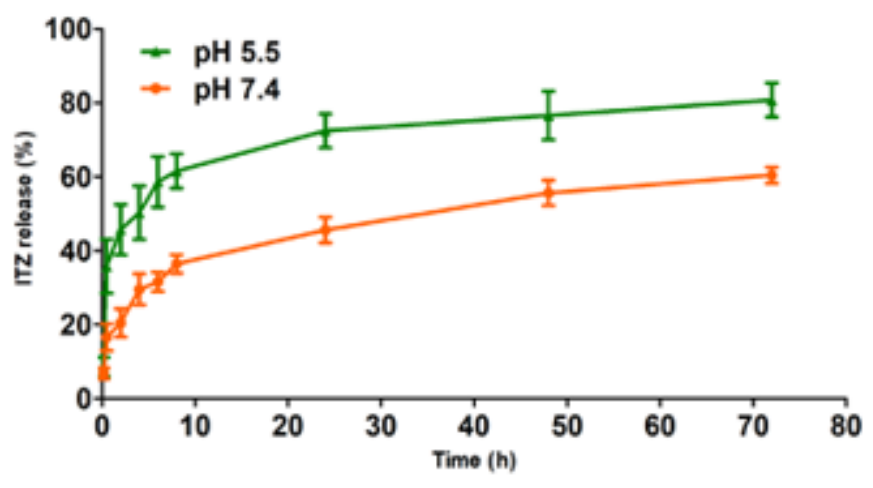

\section{Figure 3}

(A) ITZ/siRNA-loaded layer-by-layer nanoparticle delivery system. (B) Particle size and zeta potential. (C) Gel electrophoresis assay. (D) Time-dependent colloidal stability of ITZ-siRNA VEGF NPs. (E) Cumulative in vitro release profiles of ITZ-siRNAVEGF NPs in PBS release medium at $\mathrm{pH} 5.5$ and $\mathrm{pH} 7.4$, respectively. Data plots and error bars represent mean $\pm S D(n=3),(N / P=30, C / N=1 / 5$, ITZ content of $8.28 \%)$. 
(A)
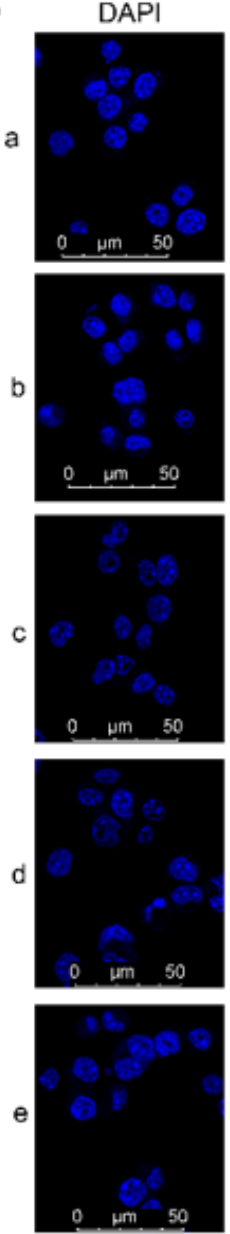

C6
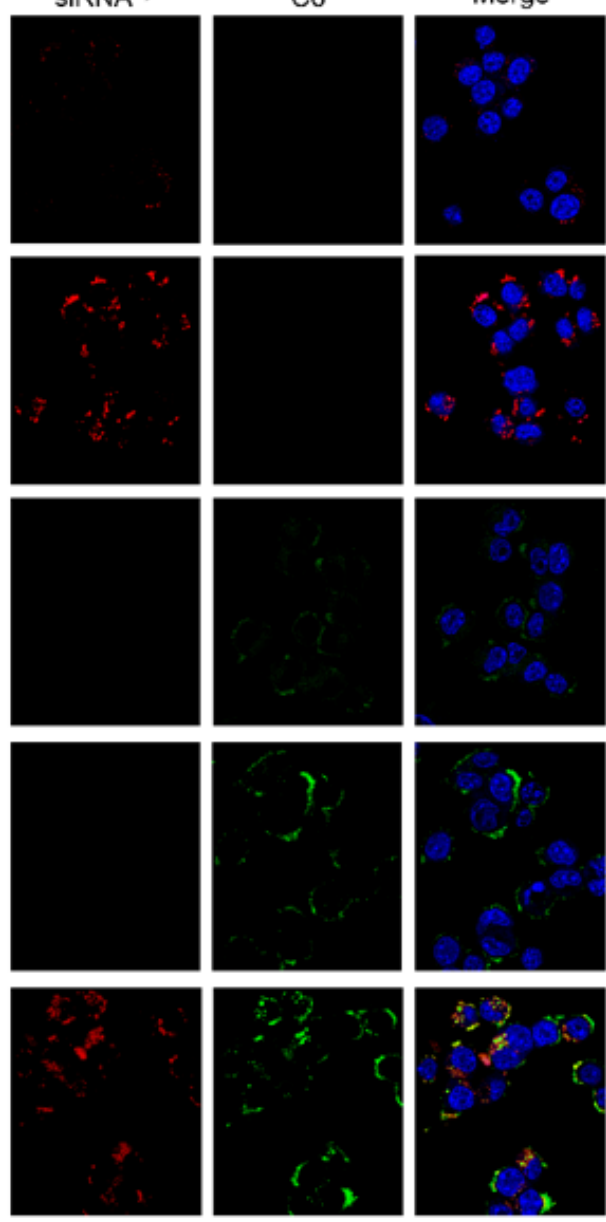
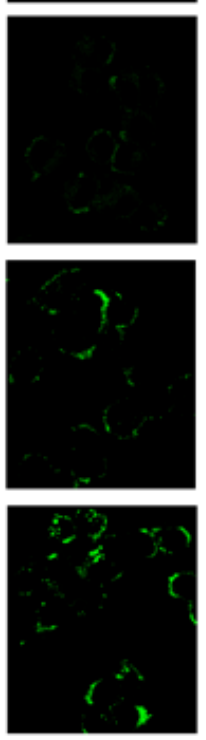
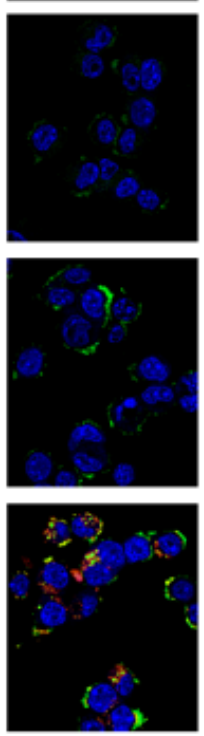

(B)
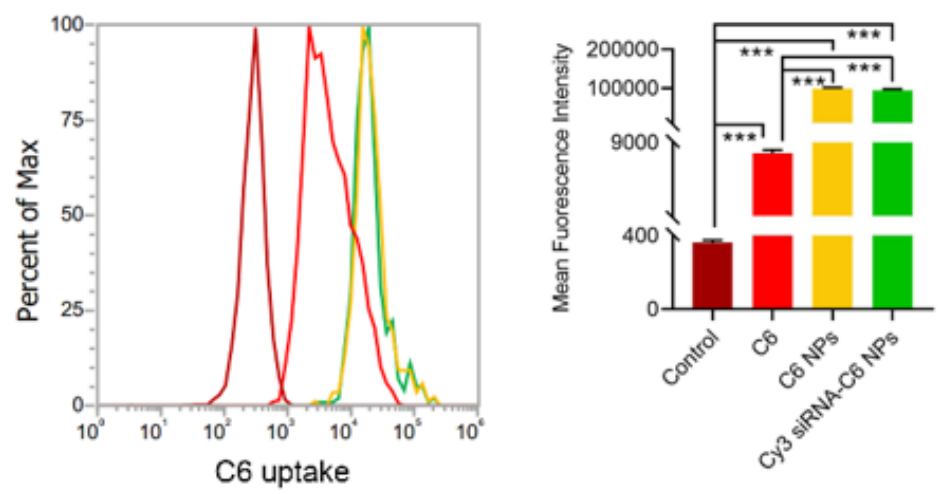

(C)
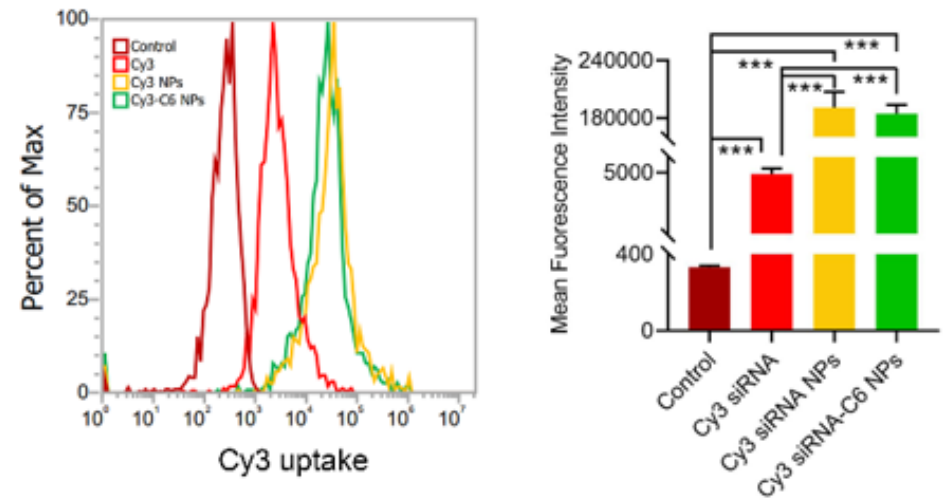

Figure 4

Cellular uptake of C6 or Cy3 siRNA in different formulations. 4T1 cells were analyzed after $4 \mathrm{~h}$ of incubation at the final concentrations of different NPs (C6 content $100 \mathrm{ng} / \mathrm{mL}$, Cy3 siRNA 50 nM, N/P = 30, $C / N=1 / 5$ ). (A) CLSM images of cellular uptake of C6-siRNA ${ }^{\text {Cy3 }}$ NPs. a) siRNA ${ }^{\text {Cy3; }}$;) siRNA ${ }^{\text {Cy3 }}$ NPs; $^{2}$ ) ITZ; d) ITZ NPs; e) siRNA Cy3-ITZ NPs. For each column, from left to right: nuclei were stained by DAPI (blue); C6 fluorescence in cells (green); Cy3 signal in cells (red); merged with neleus, C6 and siRNA ${ }^{\text {Cy3 }}$. Scale bar $=50 \mu \mathrm{m}$. (B) Quantitative analyses of C6 uptake by flow cytometry. (C) Quantitative analyses of Cy3 siRNA uptake by flow cytometry. ${ }^{\star \star \star} p<0.001$ as compared with C6 or Cy3 siRNA $(\mathrm{n}=3)$. 
(A)
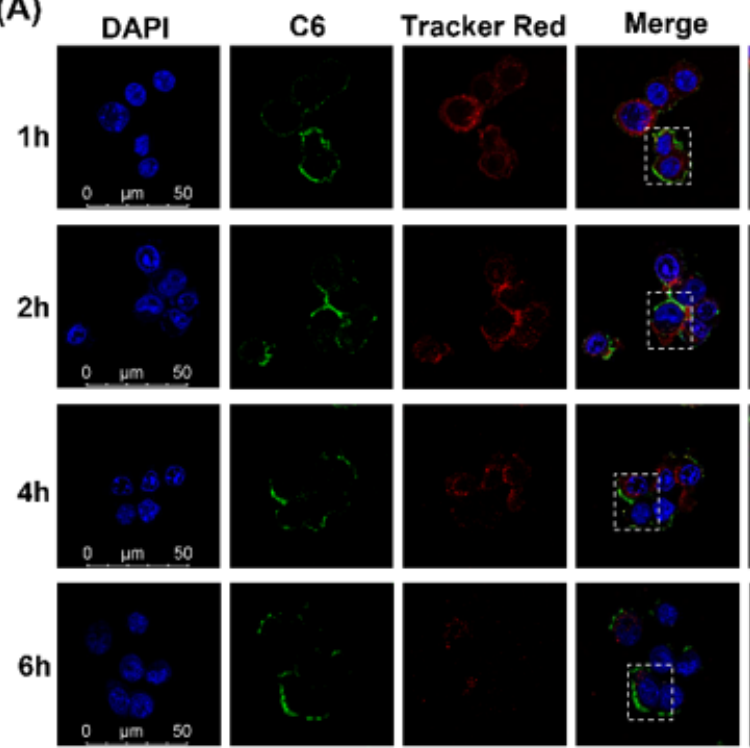
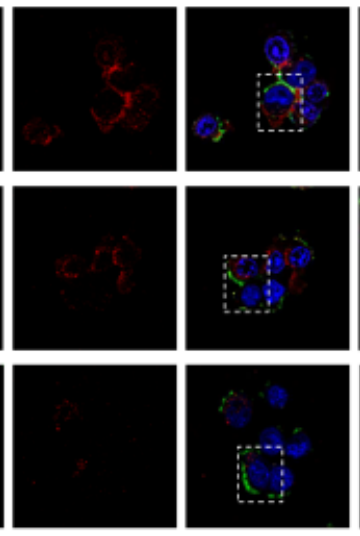

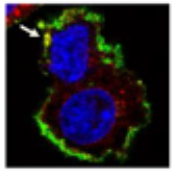

(B)

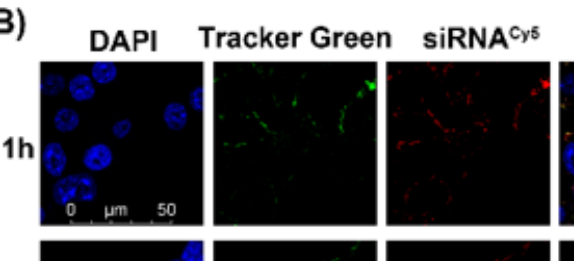

Merge
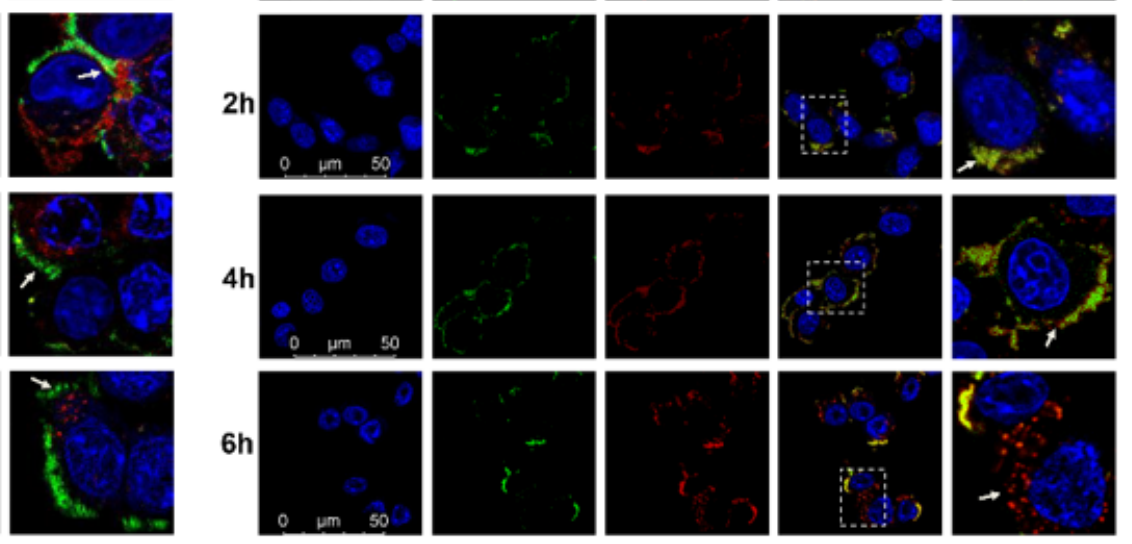

\section{Figure 5}

Endosomal escape of C6-siRNAVEGF-NPs (A) and Cy5 siRNA-ITZ NPs (B) in 4T1 cells undergoing $1 \mathrm{~h}, 2 \mathrm{~h}$, $4 \mathrm{~h}$, and $6 \mathrm{~h}$, respectively. In order to reduce the ITZ influence, the concentration of ITZ is as low as $1 \mathrm{nM}$. DAPI for nuclei staining (blue), C6 (green), Cy5 siRNA (red), LysoTracker Red (Tracker Red) and LysoTracker Green (Tracker Green) for endosomes (red and green) were recorded. Scale bar $=50 \mu \mathrm{m}$. 
(A)
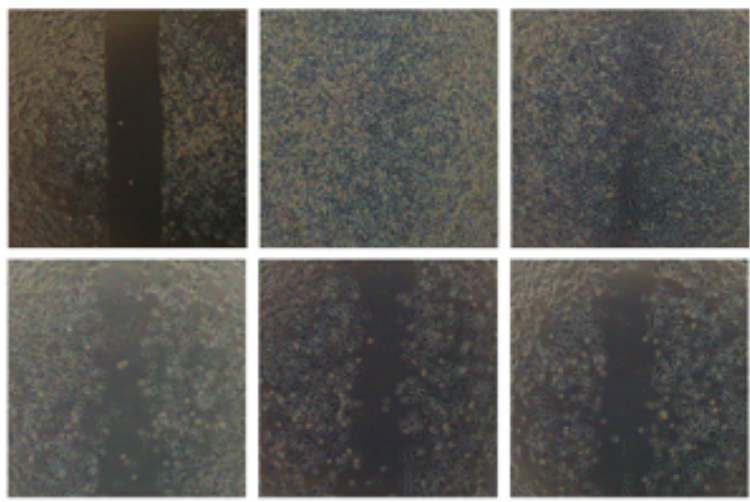

(C)
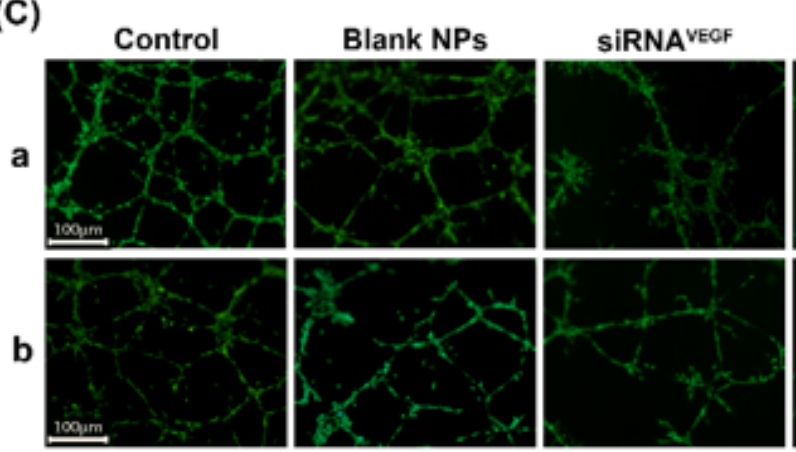

(D)

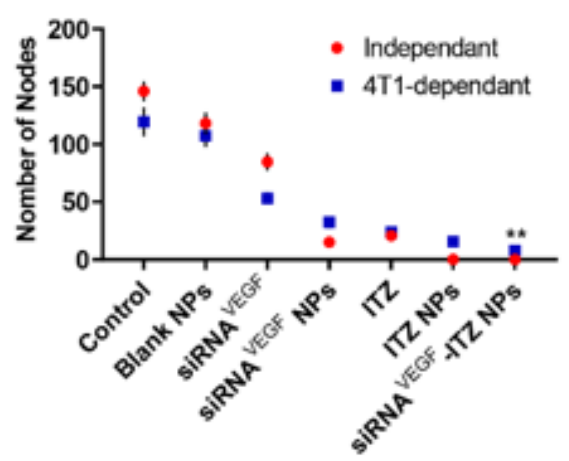

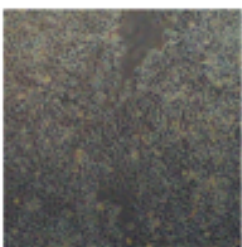

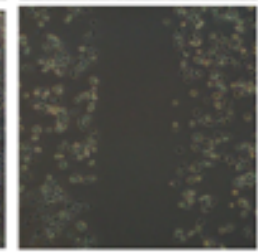

(B)
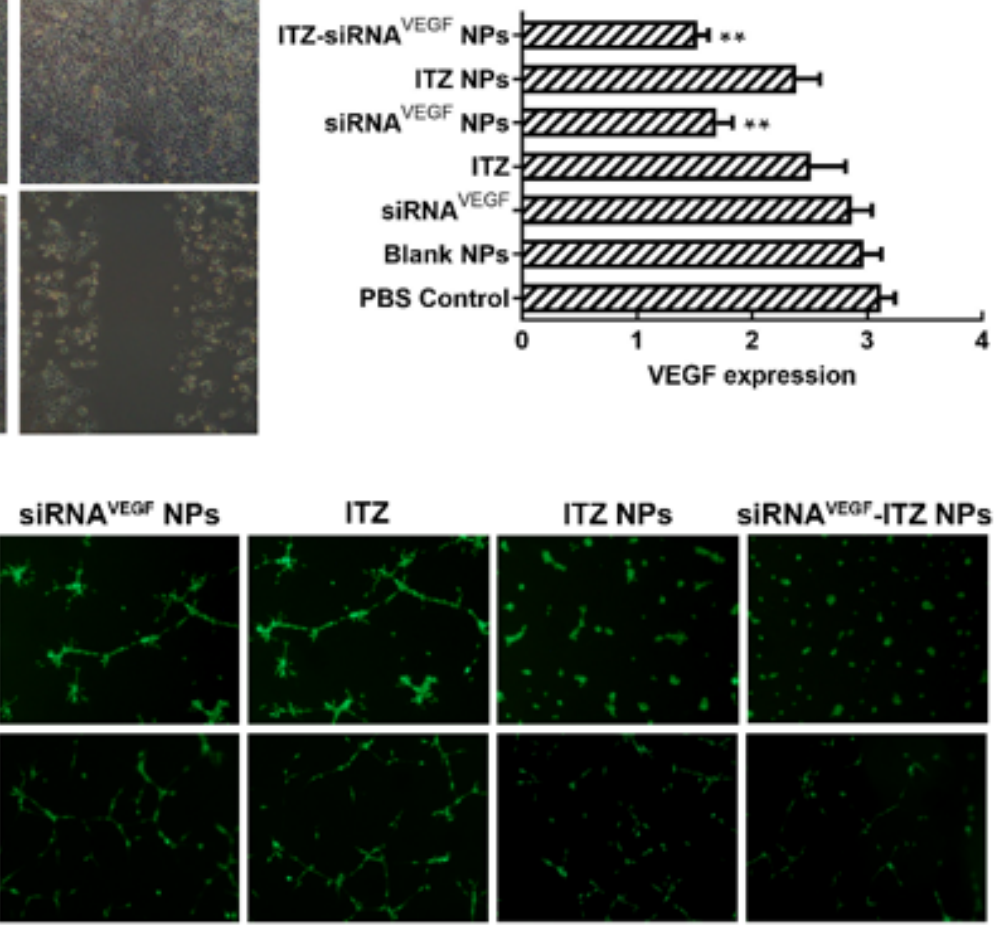

(E)

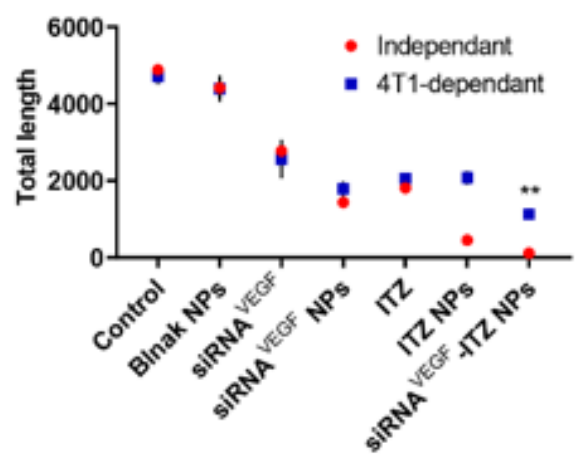

\section{Figure 6}

(A) Wound healing assay of different Nps (N/P = 30, C/N = 1/5, ITZ content: 8.28\%, 100 nM of siRNA per well) on $4 \mathrm{~T} 1 \mathrm{cells}$. The healing situation of scratch wound was observed $48 \mathrm{~h}$ after scratching using an inverted microscope. Cells without any treatment were used as control. (B) Expression of VEGF mRNA determined by quantitative real-time PCR after $48 \mathrm{~h}$ of incubation at the final concentrations of different NPs (N/P = 30, C/N = 1/5, ITZ content: $8.28 \%, 100 \mathrm{nM}$ of siRNA in per well). ${ }^{* \star} p<0.01$ as compared with control ( $n=3)$. (C) Representative fluorescent images of In vitro anti-angiogenesis efficacy of the nanoparticles. a) Inhibition of tubule formation in HUVECs on matrigel after treatment of different NPs (N/P = 30, C/N = 1/5, ITZ content: 8.28\%, $100 \mathrm{nM}$ of siRNA per well) for $24 \mathrm{~h}$. b) Inhibition of tubule formation in HUVECs on matrigel after treatment of 4T1 cells-treated "conditioned medium" for $24 \mathrm{~h}$. (D) . The quantitative analysis of the inhibition of node numbers. (E) The quantitative analysis of the inhibition of total length. Results were represented as mean $\pm S D$, $\star \star p<0.01$ as compared with control $(n=3)$. 
(A)
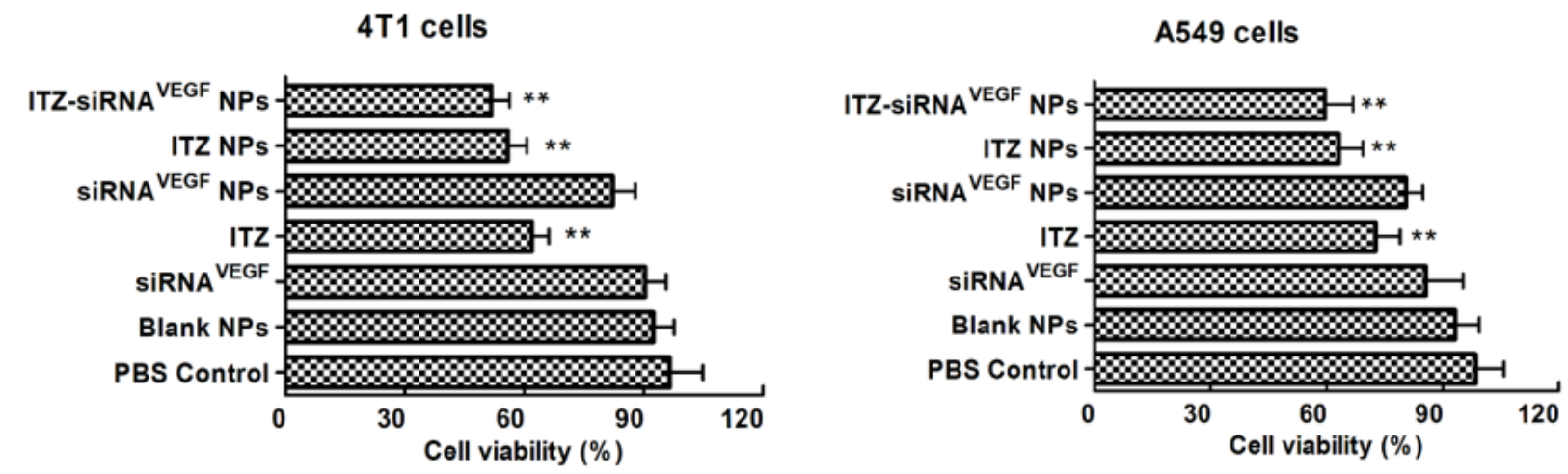

(B)
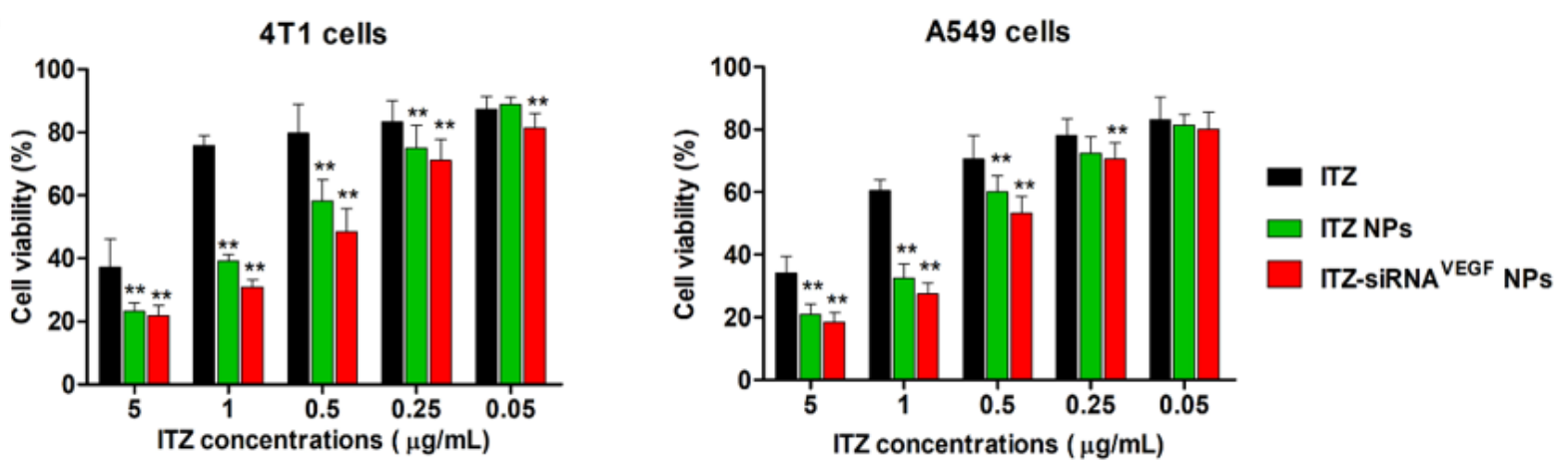

(C)
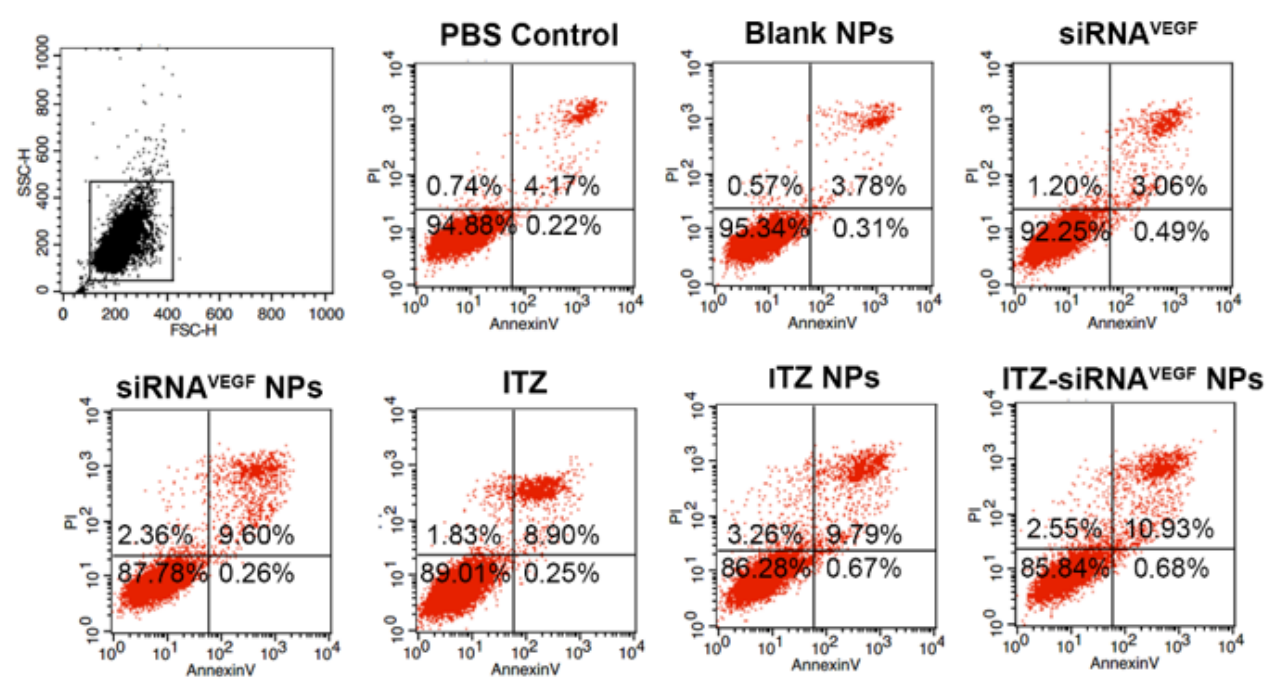

\section{Figure 7}

(A) In vitro cytotoxicity of $4 \mathrm{~T} 1$ cells and A549 cells treated with different NPs for $48 \mathrm{~h}(\mathrm{~N} / \mathrm{P}=30, \mathrm{C} / \mathrm{N}=$ $1 / 5$, ITZ content: $8.28 \%, 20 \mathrm{nM}$ of siRNA in per well). ${ }^{\star \star} p<0.01$ Vs PBS Control, Blank NPs and siRNA ${ }^{N . C}$ NPs $(n=3)$. (B) Cell viability of $4 T 1$ cells and A549 cells after treated with different NPs. The concentration of ITZ varied from 0.05 to $5 \mu \mathrm{g} / \mathrm{mL}$, and the concentration of both the scrambled siRNA and VEGF siRNA was $20 \mathrm{nM}$. ** $p<0.01$ as compared with ITZ group $(\mathrm{n}=3)$. (C) Cell apoptosis on 4T1 
cells $24 \mathrm{~h}$ after treating with various NPs (N/P = 30, C/N = 1/5, ITZ content: 8.28\%, 50 nM of siRNA per well). The cells were stained with Annexin V-FITC/PI for $15 \mathrm{~min}$.

(A)

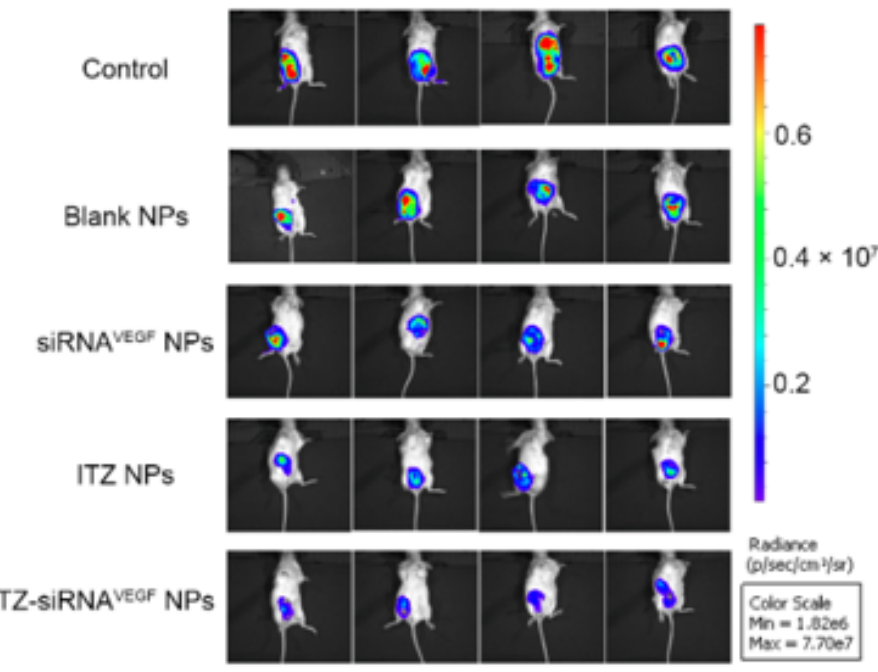

(B)

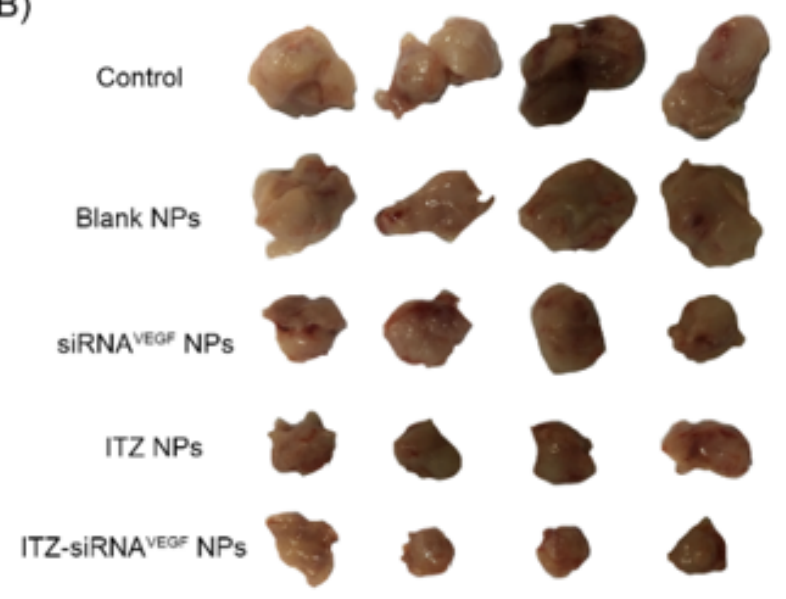

(C)

(D)
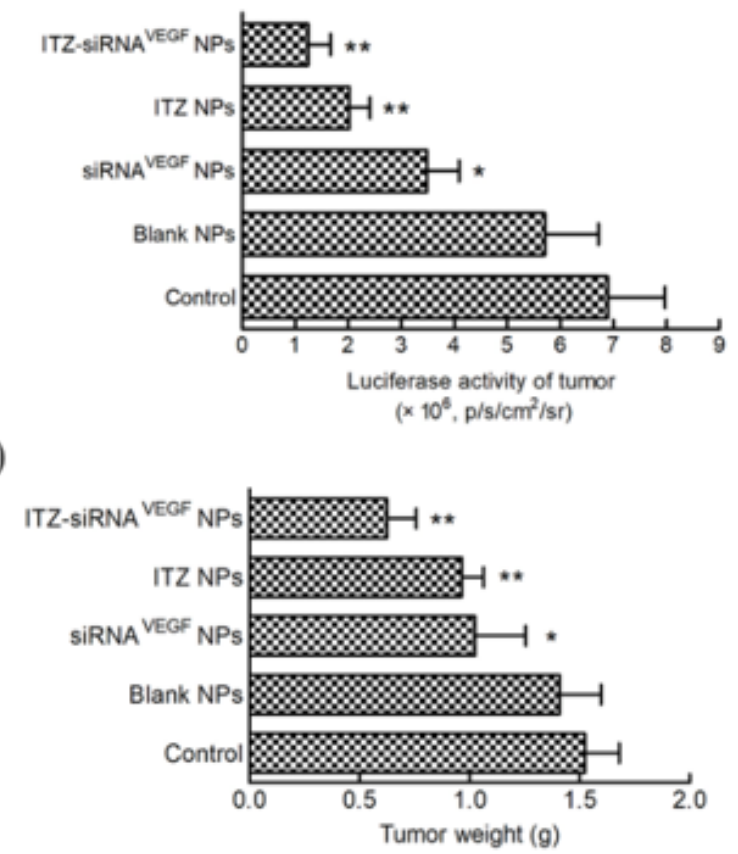

(E)

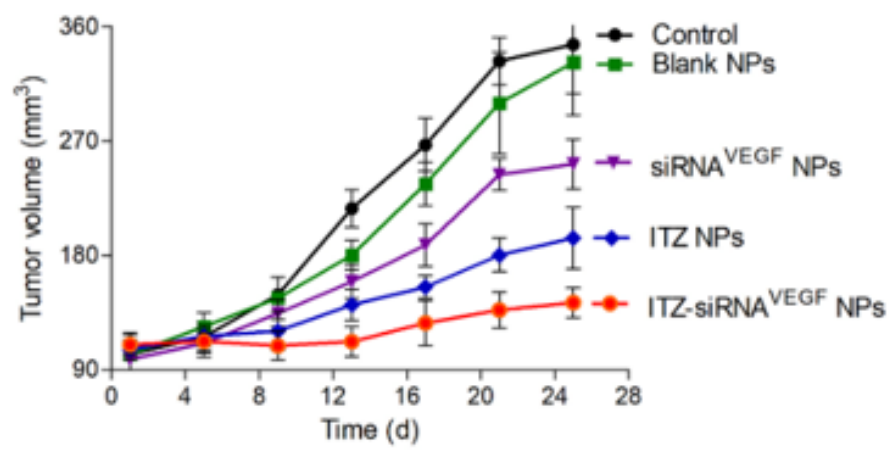

\section{Figure 8}

In vivo anti-tumor effect of systemic administration of ITZ and VEGF siRNA co-delivering NPs in 4T1 tumor-bearing mice. Female BALB/c mice (4-6 weeks old, 18-22 g) in each group were orthotopically inoculated with $1 \times 10^{5} 4 \mathrm{~T} 1^{\text {Luc }}$ cells in the fourth mammary fat pad in the right lower abdomen. The mice were intravenously injected with various formulations (N/P = 30, C/N = 1/5; ITZ content: 8.28\%). ITZ was administered at a dose of $10 \mathrm{mg} / \mathrm{kg}$, and VEGF siRNA was administered at a dose of $3 \mathrm{mg} / \mathrm{kg}$. (A) In vivo bioluminescence imaging analysis of mice after administration with various formulations. (B) The tumor photos $(n=4)$. (C) Quantitative estimation by bioluminescent analysis. ${ }^{\star} p<0.05, * \star p<0.01$ vs. saline group ( $n=3)$. (D) The weight of tumors due to in vivo antitumor effects of ITZ and VEGF siRNA codelivering NPs. ${ }^{*} p<0.05,{ }^{*} p<0.01$ vs. saline group $(\mathrm{n}=4)$. (E) The changes in tumor volume due to in vivo antitumor effects of ITZ and VEGF siRNA co-delivering NPs $(n=4)$. 
(A)

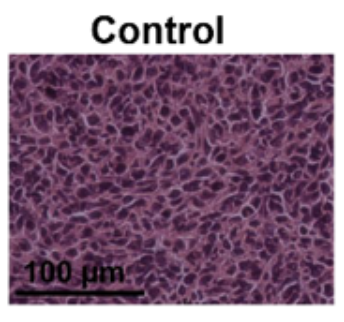

HE

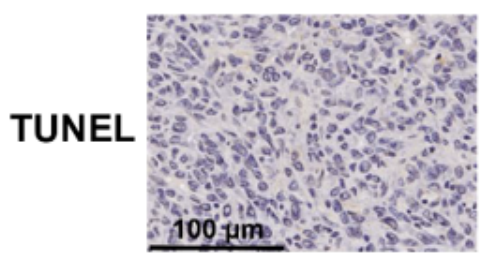

$100 \mu \mathrm{m}$
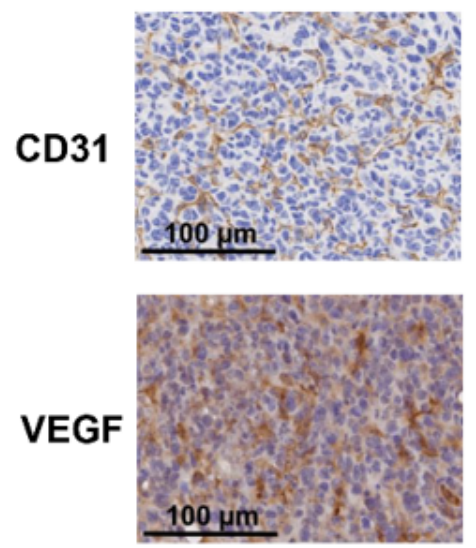

(B)

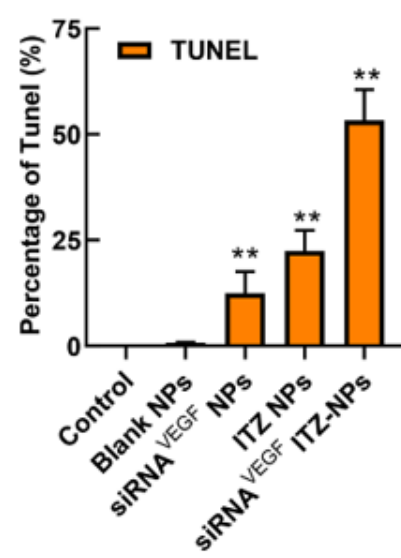

Blank NPs
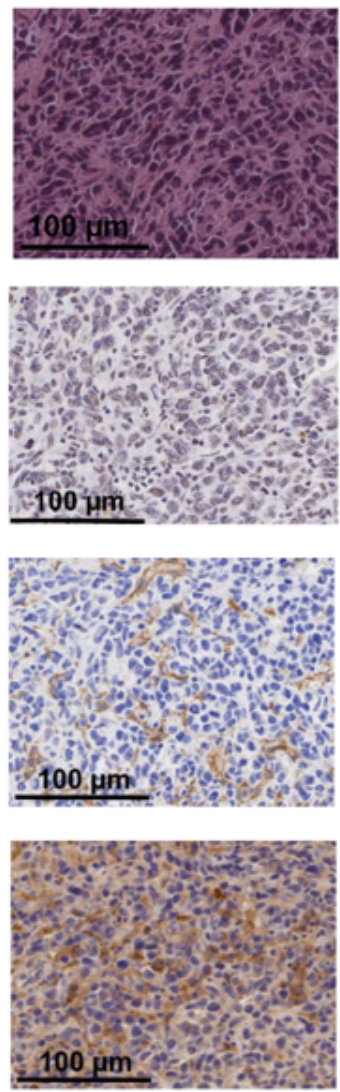

SIRNA ${ }^{\text {VEGF NPS }}$
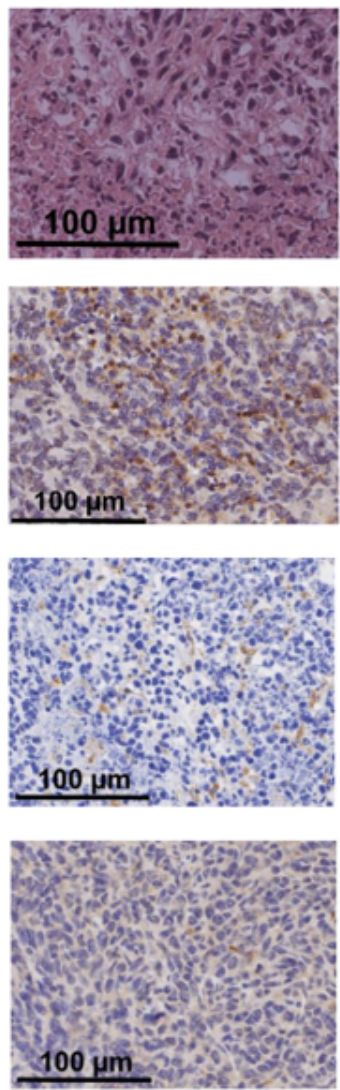

ITZ NPs
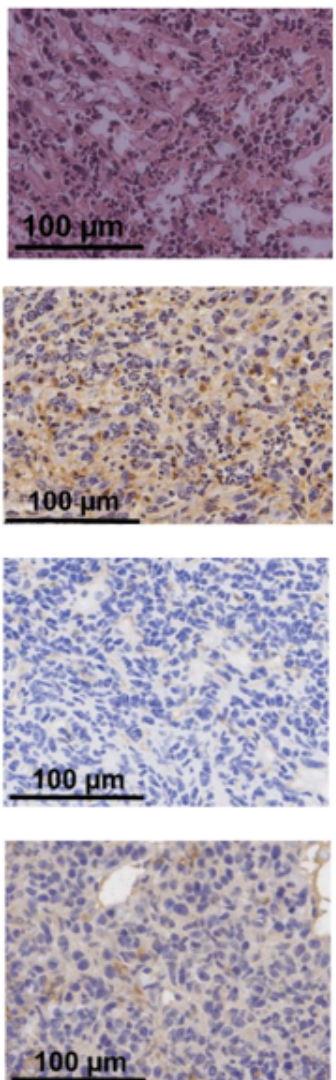

SIRNAVEGF-ITZ NPS
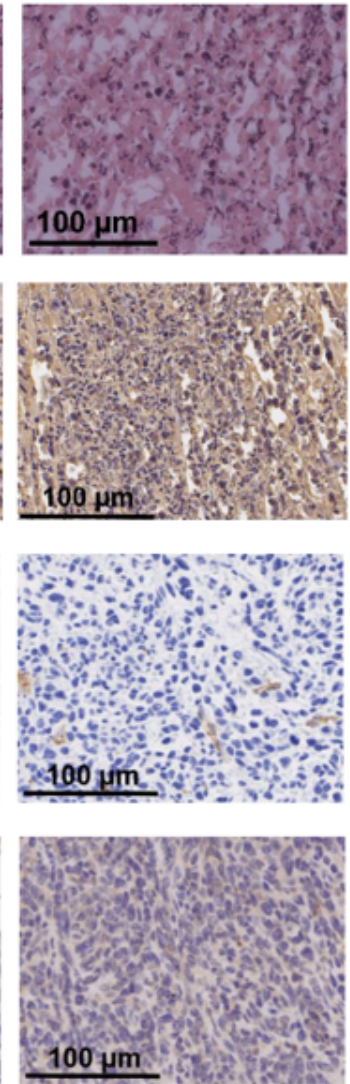
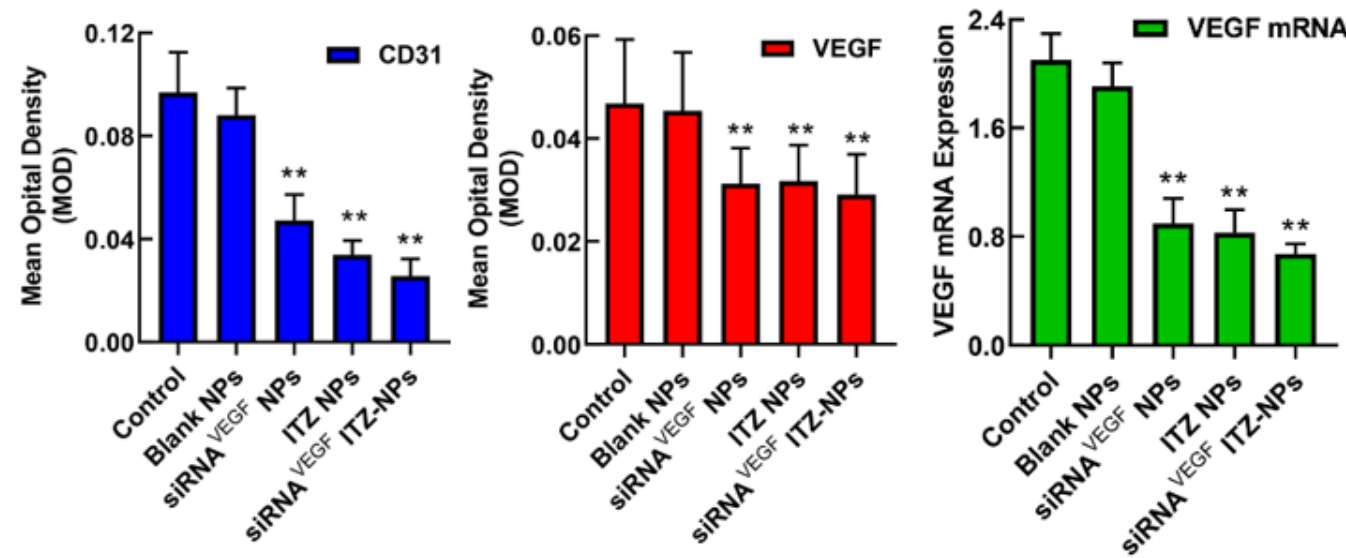

Figure 9

(A) Histological analysis of the tumor tissues after treatment. The HE, TUNEL staining, and immunofluorescence of CD31 and VEGF proteins in tumor tissues harvested from different groups. Scale bar $=100 \mu \mathrm{m}$. (B) Apoptosis rate (Percentage of TUNEL), quantitate analysis of CD31 and VEGF expression and tumor levels of VEGF mRNA after systemic administration of ITZ and VEGF siRNA codelivery NPs (N/P = 30, C/N = 1/5; ITZ content: 8.28\%) in 4T1 Luc tumor-bearing mice. ${ }^{* \star} p<0.01,{ }^{\star} p<0.05$ vs. saline $(n=4)$. 


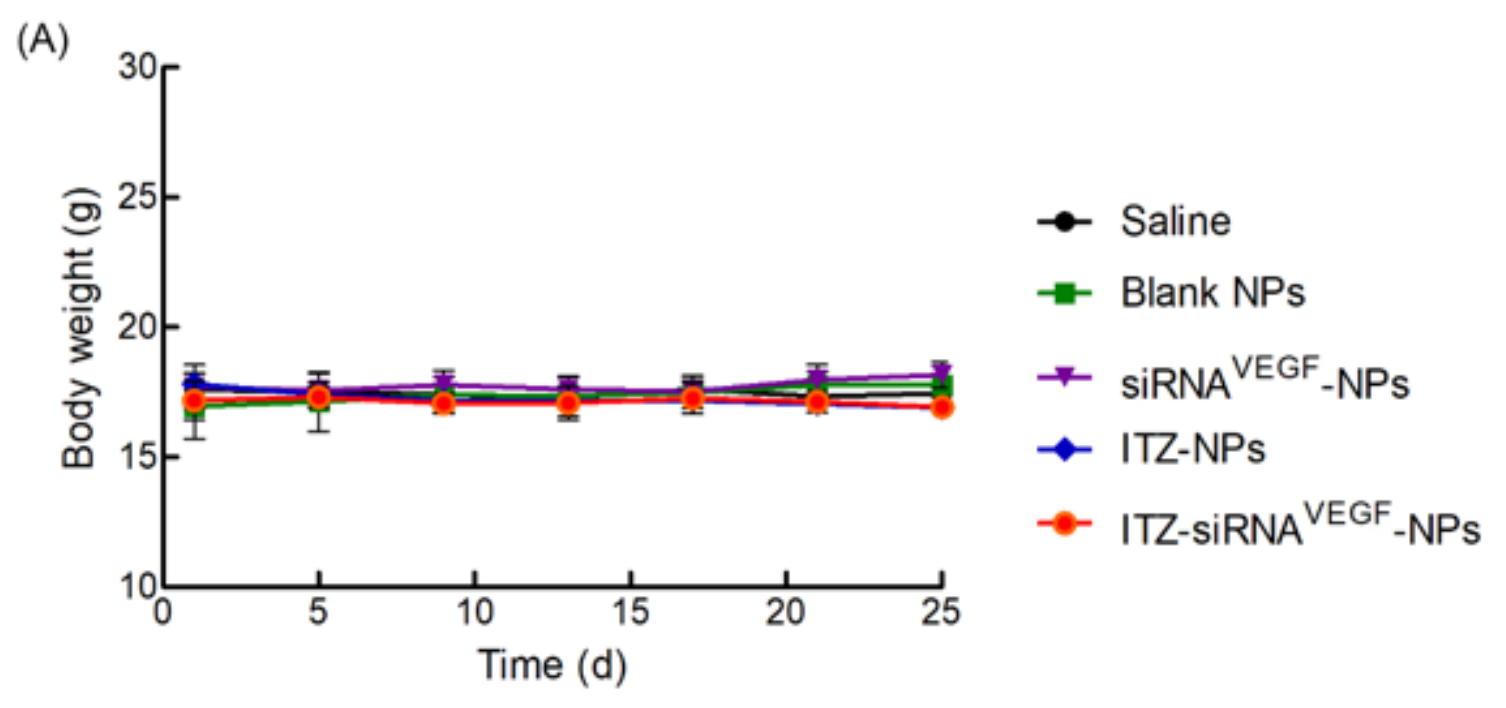

(B)

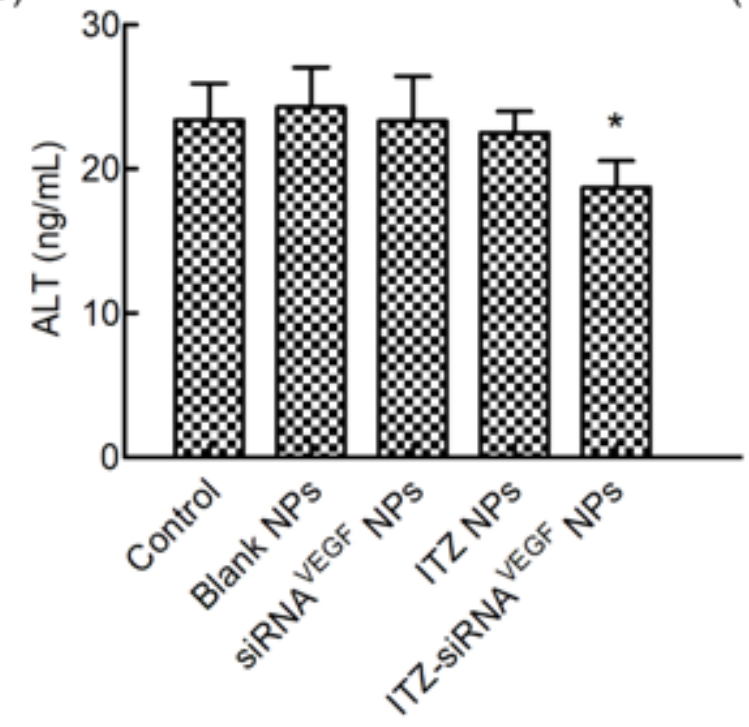

(C)

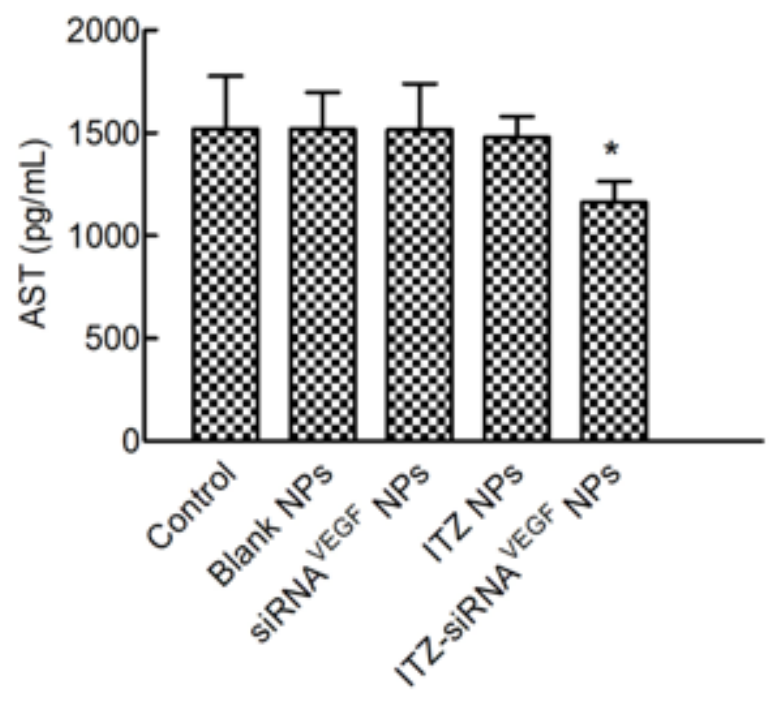

Figure 10

(A) The changes of body weight of in vivo anti-tumor effects of systemic administration of ITZ and VEGF siRNA codelivery NPs in 4T1 $1^{\text {Luc }}$ tumor-bearing mice. $(n=4)$. (B) Mouse ALT levels in the serum of the tumor-bearing mice at the end time point of the animal experiment were determined by ELISA $(n=4)$.

Data are provided as mean \pm SD. ${ }^{*} p<0.05,{ }^{\star \star} p<0.01$ vs. saline. (C) Mouse AST levels in the serum of the tumor-bearing mice at the end time point of the animal experiment were determined by ELISA $(n=4)$. Data are provided as mean \pm SD. ${ }^{*} p<0.05$, ${ }^{\star \star} p<0.01$ vs. saline. 